\title{
Cadenas de valor forestal en Moyobamba, San Martín \\ Oportunidades para pequeños productores
}

Frangi Valencia

Peter Cronkleton

Maite Bustamante 



\title{
Cadenas de valor forestal en Moyobamba, San Martín
}

\section{Oportunidades para pequeños productores}

\author{
Frangi Valencia \\ Centro Para la Investigación Forestal Internacional (CIFOR) \\ Peter Cronkleton \\ Centro Para la Investigación Forestal Internacional (CIFOR) \\ Maite Bustamante \\ Centro Para la Investigación Forestal Internacional (CIFOR)
}


Documento de trabajo 272

(c) 2021 Centro para la Investigación Forestal Internacional

(c) (1) El contenido de esta publicación se encuentra bajo una licencia Creative Commons Attribution 4.0 International (CC BY 4.0), http://creativecommons.org/licenses/by/4.0/

DOI: $10.17528 /$ cifor/008330

Valencia, F., Cronkleton, P. y Bustamante, M. (2021). Cadenas de valor forestal en Moyobamba, San Martín: Oportunidades para pequeños productores. Documento de trabajo 272. Bogor, Indonesia: CIFOR.

CIFOR

Jl. CIFOR, Situ Gede

Bogor Barat 16115

Indonesia

$T+62(251) 8622-622$

$\mathrm{F}+62(251) 8622-100$

E cifor@cgiar.org

\section{cifor.org}

Quisiéramos agradecer a todos los socios financieros que apoyaron esta investigación a través de sus contribuciones al Fondo de CGIAR. Para ver la lista de donantes del Fondo, visite: http://www.cgiar.org/about-us/our-funders/

Cualquier opinión vertida en este documento es de los autores. No refleja necesariamente las opiniones de CIFOR, de las instituciones para las que los autores trabajan o de los financiadores. 


\section{Tabla de Contenido}

Executive Summary v v v v v v v v v v

Resumen viii

1 Introducción $\quad 1$

2 Metodología $\quad 3$

2.1 Sondeo del mercado forestal en San Martín 3

2.2 Estudio de cadenas de valor forestal en Moyobamba 4

3 Tres cadenas de valor forestal con potencial para pequeños productores $\quad 8$

3.1 Madera aserrada $\quad 8$

\begin{tabular}{lr}
3.2 & Pie derecho \\
\hline .3 & 14
\end{tabular}

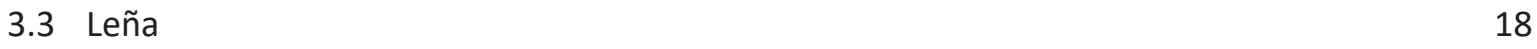

4 Cuellos de botella $r 2$

5 Recomendaciones $\quad 25$

$\begin{array}{lr}\text { Referencias } & 28\end{array}$

$\begin{array}{lr}\text { Annexos } & 29\end{array}$

1 Actores entrevistados en la primera fase del estudio en San Martín 29

2 Frutos observados en los mercados en Moyobamba $\quad 30$ 


\section{Lista de figuras y tablas}

\section{Figuras}

1 Cuartones apilados en aserradero rural en el distrito de Soritor, provincia de Moyobamba 9

2 Cadena de valor de madera aserrada 11

3 Puesto de venta de pie derechos en Tarapoto, San Martín 15

4 Cadena de valor del pie derecho 17

5 Leña apilada en vivienda y disponible para su venta en el distrito de Jepelacio, San Martín 18

6 Cadena de valor de la leña $\quad 20$

\section{Tablas}

1 Informantes entrevistados $\quad 5$

2 Productos más vendidos por los aserraderos urbanos $\quad 11$

3 Especies de madera blanda más utilizadas para producir madera aserrada para construcción y muebles

4 Especies de madera dura más utilizadas para producir madera aserrada para construcción y muebles

5 Especies de madera blanda más utilizadas para producir pie derecho 17

6 Especies de madera dura más utilizadas para producir pie derecho 18 


\section{Executive Summary}

\section{Introduction}

This paper reports on analysis of forest value chains that involve smallholder producers in the Moyobamba province of San Martin. The research was carried out as part of the project "Piloting Approaches to Rural Advisory Services in Support of Scaling the Agroforestry Concessions Scheme in Peru (PARA)" led by the World Agroforestry Centre (ICRAF) ${ }^{1}$. The objective of the study was to evaluate forest value chains in San Martin, Peru to identify products and systems with potential for improving sustainable livelihood opportunities for smallholder famers that may be eligible to participate in agroforestry concessions schemes (known by the Spanish language acronym CUSAF) being implemented by the regional government. This report describes the value chains of three selected products, summarizes the role played by smallholder farmers and the challenges they face, and concludes by identifying possible recommendations for enhancing opportunities for smallholder producers.

\section{Methods}

Data collection for this value chain analysis took place over two stages. An initial rapid appraisal (or sondeo) of principal markets in San Martin took place between August 2-14, 2019. During the appraisal, the CIFOR field team visited forest product markets and industries in Tarapoto, Lamas, Moyobamba, Jepelacio and Soritor. The visits allowed the team to observe market conditions and activities as well as to informally interview vendors, workers and consumers involved with the commercialization of diverse forest and agricultural products. The team also visited and interviewed key informants from the regional government, local industries, and non-governmental organizations to gather information on their perceptions of market characteristics and opportunities. A total of 56 informants were interviewed informally during this stage.

A second stage of fieldwork was carried out by the CIFOR team from December 4 to $21^{\text {st }}, 2019$ in the Moyobamba province with emphasis on the municipalities of Jepelacio and Soritor. Information on selected value chains was gathered during semi-structured interviews with informants identified using snowball sampling techniques starting with informants identified during the appraisal stage. Interviews focused on informant roles in the sector, principal activities, sources of supply, destination of products and perceptions of market flows and opportunities. In total, the team interviewed 55 informants during these field visits.

\section{Key results for selected value chains}

This analysis identified the three forest product value chains with the greatest potential for sustainable production options to improve the livelihoods of small producers receiving CUSAF contracts. During an initial appraisal of regional markets, a wide variety of timber and non-timber forest products (NTFPs), including fibers, fruits, mushrooms, and edible insects were considered. However, the three product chains that offered greatest potential are those for timber, poles, and firewood.

1 The PARA project is an initiative implemented by the World Agroforestry Centre (ICRAF), in collaboration with the NGO Solidaridad, the Center for International Forestry Research (CIFOR) and Freiburg University. This project has been funded by the German Federal Ministry for Economic Cooperation and Development (BMZ) on behalf of Deutsche Gesellschaf für Internationale Zusammenarbeit (GIZ) through the International Fund for Agricultural Research (FIA). 
Timber: The municipalities where the research project took place are reportedly the principal regional sources of timber (round wood and sawn wood) supplying the capital (although large dimension timber and some preferred species are sourced from the lowlands). In these municipalities, smallholders provide a major source of timber for the existing value chains present, but smallholders have a weak position due to the lack of legal authorization to extract wood and have limited access to markets. Key actors in the timber value chain at these sites are urban sawmills and intermediaries that finance forest operations and often act as wholesalers. More recently, small-scale mills and carpentry shops have sprung up smaller population centers and operate as service providers or competitors for the larger scale industries. The 'industrial' actors dominate the local timber market and smallholders periodically sell small volumes of wood to them, usually as standing trees at low prices. Trees are felled on farm and transformed into sawn lumber (cut into dimensions known locally as cuartones and tablones) to facilitate transport to mills for additional processing. Farmers have little or no involvement once the wood leaves their property, or sometimes even once trees are sold.

There are several challenges that limit options for smallholders in timber value chains. Informants reported that forest resources in areas occupied by smallholders have suffered from over exploitation and the lack of sustainable management practices. As a result, the most desirable timber species have disappeared and the remnant forests on smallholder plots are frequently degraded. While there has been some development of plantations as a result of development initiatives or spontaneous efforts by farmers, plantation forestry is underdeveloped, although some farmers reported having experimented within agroforestry systems. When farmers do have timber to market, it is difficult for them to gain legal approval to harvest or transport the wood. Also, farmers lack information of markets and technical processes. Finally, farmers reportedly lack leverage to negotiate with more powerful economic actors. They enter as individuals and lack information about market opportunity and legal options.

Poles: Poles are small dimension timber $(10 \mathrm{~cm}$ to $15 \mathrm{~cm})$ cut into 3 and $6 \mathrm{~m}$ lengths that are commonly sold as supports for construction. Most poles are sourced from smallholder farms, often produced in second growth fallows, although some poles are by-products that result when plantations are thinned. Some species can still be found in remnant forests. Lately, bamboo has been reportedly appearing in markets as an alternative option for poles.

The key actor in the value chain for poles are urban wholesalers that supply large quantities to construction companies, projects or even home builders. For farmers, while poles are a lower value product than other timber, the income derived from the sale can provide an important supplement to livelihoods using by-products from other production activities that otherwise would go unused. Wholesalers periodically roam rural zones to find producers that are able to sell juvenile trees, often when second growth fallows are set to be cleared for cultivation. Farmers usually depend on these buyers in their area to make a sale.

There are several challenges for smallholder farmers intent on playing more active role in this value chain. Farmers frequently have suitable trees that could be sold as poles; however, not always in quantities that buyers need. Also, they usually lack legal authorization to transport poles to urban markets and also lack information about market opportunities.

Firewood: Smallholders produce fuelwood for subsistence use but also sell it periodically. They use a diversity of species, often from limbs and scrap wood left over from tree removal or logging. This also includes species (Inga sp.) used as shade for coffee when these trees are removed. There is a significant regional fuelwood market for the preparation of smoked meats, an urban market for making bread (bakeries) and fuelwood is also sold to urban consumers for home use.

Several of the preferred species for fuelwood have become rare in the municipalities studied due to over exploitation. Informants reported that significant volumes of charcoal are brought in from outside the region. 
Similar to poles, there are wholesalers established in urban peripheries that specialize in the marketing of fuelwood. They travel rural areas seeking out farmers with fuelwood to cut and sell. When in need, famers may cut fuelwood and stack near roads to attract the attention of buyers. At times, farmers also transport small quantities of fuelwood to nearby population centers for sale.

As an economic option, there are several challenges for smallholders with fuelwood. The principal issue is gaining legal authorization to transport fuelwood for sale. Rural producers also lack information and have weak market networks, so are dependent on itinerate buyers to make sales.

\section{Options to address existing challenges}

Adjust legal options to support the sustainable management and commercialization of forest products: Legal authorization to commercialize forest products is a major bottleneck to developing livelihood options based on the selected value chains. To allow more proactive roles for smallholders, the regional government should simplify and streamline requirements and processes for legalizing sustainably produced products. To avoid duplication of efforts, regulatory steps should be aligned with processes for authorizing CUSAF to facilitate approval of smallholder production options. For example, while collecting information to validate qualifications for CUSAF, regional authorities should use processes that also gather necessary information to register existing plantations and agroforestry systems. This could strengthen management incentives and options for future commercialization of authorized forest products.

\section{Develop plantation and agroforestry options:}

While there have been past initiatives to promote forest plantations and agroforestry systems, there seems to be great potential for developing and promoting appropriate forestry options for smallholder systems. Efforts should be made to learn from farmer experimentation and indigenous knowledge to ensure recommendations are adapted to local conditions. The promotion of species mix should focus on species selected by farmers and demanded by local market actors.

\section{Strengthen forest producer organizations and networks:}

Efforts should assist producers to organize through the creation of cooperatives or by expanding existing organizations to address forest product issues. These organizations should emphasize collective negotiation with wholesalers and industrial buyers to give farmers greater leverage and economies of scale to negotiate better prices or more equitable transactions. These groups would also facilitate the dissemination of technical support, administrative assistance, and information dissemination.

\section{Capacity building to develop commercial knowledge and management/technical skills:}

Assist smallholders to access and use information about market opportunities and regulations associated with participation. Management and commercial capacity could be strengthened by providing practical training in basic skills like calculation of wood volume or improved planning.

\section{Adapt plans to include gender inclusive strategies:}

Household production systems management at selected sites are managed by women and men, so gender inclusive strategies are fundamental to ensuring that both men and women are included and participate. Initiatives should take actions to explicitly include women in invitations, planning and activities. Efforts should be made to guarantee that information dissemination includes women as key target audiences. Monitoring of progress initiatives should include indicators to track inclusion of both men and women and evaluate benefit of programs on both. 


\section{Resumen}

La Ley Forestal y de Fauna Silvestre del 2011 creó un mecanismo que permite implementar sistemas sostenibles de producción permanente: los contratos de Cesiones en Uso para Sistemas Agroforestales (CUSAF). Este mecanismo representa una oportunidad para conservar y recuperar ecosistemas forestales y, simultáneamente, generar medios de vida sostenibles en beneficio de pequeños productores. En el marco del proyecto "Piloting Approaches to Rural Advisory Services in Support of Scaling the Agroforestry Concessions Scheme in Peru (PARA)" a cargo del World Agroforestry Centre (ICRAF) ${ }^{2}$ se llevó a cabo una investigación para evaluar las cadenas de valor forestales que ofrecen oportunidades para pequeños productores elegibles para recibir contratos de Cesiones en Uso para Sistemas Agroforestales (CUSAF) en la provincia de Moyobamba, departamento de San Martín. El objetivo fue identificar aquellos productos y sistemas con mayor potencial para diversificar los medios de vida de los pequeños productores locales, y las condiciones necesarias para promover que tengan una participación rentable y sostenible en estas cadenas de valor. Este informe describe las cadenas de valor de los tres productos identificados con mayor potencial para beneficiar a los pequeños productores (madera aserrada, puntales, leña); analiza el rol que cumplen los pequeños productores actualmente en estas cadenas y los retos que enfrentan; $y$ ofrece recomendaciones para incrementar sus oportunidades.

2 ICRAF cuenta con financiamiento del Ministerio Federal para Cooperación Económica y Desarrollo, de Alemania. 


\section{Introducción}

En el año 2011, la promulgación de la Ley Forestal y de Fauna Silvestre representó un hito en el esfuerzo por reconocer a las familias que ocupan tierras forestales y alentarlas a adoptar prácticas de manejo forestal sostenible. Uno de sus principales mecanismos para ello fue incluido en la norma del artículo $\mathrm{N}^{\circ} 58$ de su reglamento: los contratos de Cesiones en Uso para Sistemas Agroforestales (CUSAF). Estos contratos autorizan a ciudadanos que habitan áreas de dominio público a acceder de manera formal a los recursos forestales de sus parcelas con fines de producción o recuperación. De esta manera, tienen el potencial de contribuir a generar medios de vida sostenibles y formales.

Los contratos CUSAF podrían beneficiar a los 120000 pequeños productores de la Amazonía peruana que ocupan un aproximado de 450000 hectáreas de bosque sin derechos formales de propiedad (Robiglio 2018). Estos contratos son otorgados por la Autoridad Regional Forestal y de Fauna Silvestre (ARFFS) por un plazo renovable de 40 años, en áreas menores a 100 ha. Para acceder a ellos, los beneficiarios deben demostrar que ocupan el terreno a concesionar desde antes del año 2011 y comprometerse a evitar la deforestación, mantener los bosques remanentes, establecer sistemas agroforestales en al menos el $20 \%$ de la parcela e implementar prácticas sostenibles de uso de la tierra.

Sin embargo, el gran potencial de este mecanismo actualmente es insuficientemente aprovechado debido a que la implementación de estos contratos es aún incipiente. En la región San Martín, hasta finales del año 2019, solo se otorgaron 14 contratos de CUSAF para un total de 120,3 ha en las provincias Lamas y Mariscal Cáceres (GORESAM 2019). Ante esta situación, surge el proyecto PARA "Piloto de servicios de asistencia técnica rural en apoyo a las Cesiones en Uso para Sistemas Agroforestales" (Piloting Approaches to Rural Advisory Services in Support of Scaling the Agroforestry Concessions Scheme in Peru PARA)", una iniciativa implementada por el Centro Internacional de Investigación Agroforestal (ICRAF), en convenio con la ONG Solidaridad, el Centro de Investigación Forestal Internacional (CIFOR) y la Universidad de Freiburg. Este proyecto está financiado por el Ministerio Federal Alemán de Cooperación Económica y Desarrollo (BMZ) por encargo de la Deutsche Gesellschaft für Internationale Zusammenarbeit (GIZ) a través del Fondo Internacional de Investigación Agrícola (FIA). El proyecto PARA tiene por objetivo de apoyar al gobierno de San Martín a desarrollar una estrategia que le permita implementar contratos CUSAF en la región.

En el marco del proyecto, CIFOR ha desarrollado el presente estudio que tiene como objetivo evaluar las cadenas de valor de productos forestales existentes en la región San Martín e identificar cuáles de ellas tienen el mayor potencial para proveer de medios de vida sostenibles y rentables a los pequeños productores elegibles para obtener contratos de CUSAF en la región. Con ello, busca contribuir a que las estrategias de asistencia técnica rural a ser ejecutadas en el marco del proyecto PARA sean informadas y efectivas.

Para elaborar esta investigación, entre agosto y diciembre de 2019, se desarrolló un levantamiento de información en campo en los distritos de Jepelacio y Soritor, de la provincia de Moyobamba. En un primer momento, se realizó un sondeo de los mercados de productos forestales, que permitió identificar los tres productos con mayor potencial de beneficiar a los pequeños productores locales: la madera aserrada, los puntales o pie derechos, y la leña. En una segunda etapa, se profundizó el análisis de las cadenas de valor de esos tres productos seleccionados mediante el estudio de sus etapas productivas, actores y principales dinámicas.

El presente documento da cuenta de los resultados de este estudio. Inicia con una presentación de la metodología empleada. Posteriormente, presenta las principales características de las tres cadenas 
de valor de los productos seleccionados, enfatizando sus características generales y las especies de madera que utilizan. A continuación, explica los cuellos de botella que afectan negativamente la participación de los pequeños productores en estas. Finalmente, presenta recomendaciones para superar estos cuellos de botella y crear condiciones favorables a los pequeños productores.

Entre sus principales hallazgos, este estudio advierte que, si bien los pequeños productores locales ya cumplen un rol importante en estas cadenas por ser sus principales proveedores de materia prima, existen cinco cuellos de botella que deben ser atendidos para lograr que su participación sea sostenible y rentable. En primer lugar, la falta de autorizaciones legales para que los pequeños productores puedan extraer y transportar madera. En segundo lugar, la degradación de los bosques y la desaparición de las especies de árboles con mayor demanda en sus parcelas. En tercer lugar, la vulnerabilidad de los pequeños productores al negociar con actores más poderosos. En cuarto lugar, la falta de acceso a información de los pequeños productores sobre las condiciones del mercado y los procedimientos técnicos. Finalmente, la poca visibilidad del rol de la mujer en las actividades productivas. 


\section{Metodología}

La información para el presente análisis fue obtenida en dos etapas. En la primera, se llevó a cabo un sondeo exploratorio del mercado forestal. Este permitió conocer los aspectos más resaltantes del funcionamiento de los mercados de productos forestales en San Martín, con especial énfasis en los de Moyobamba. Asimismo, permitió identificar las tres cadenas de valor con mayor potencial de beneficio para los pequeños productores. Estas tres cadenas fueron el foco del análisis de la segunda etapa del estudio, que profundizó en sus procesos, actores, desafíos y potencialidades.

\subsection{Sondeo del mercado forestal en San Martín}

La primera etapa, consistente en el sondeo exploratorio del mercado forestal, se llevó a cabo entre los días 2 y 14 de agosto de 2019 en los distritos de Tarapoto, Lamas, Moyobamba, Jepelacio y Soritor, en el departamento de San Martín. En esta se utilizó el método de sondeo (Hildebrand, 1981) que consistió en una breve evaluación de campo para conocer el contexto local. Los objetivos del sondeo fueron explorar los principales mercados de productos forestales del departamento e identificar: la diversidad de productos forestales que se comercializan, los actores que participan en sus cadenas de valor y sus principales dinámicas comerciales.

En esta etapa se realizó una revisión de artículos académicos y de estadísticas oficiales para una primera aproximación al contexto, así como de la normativa existente y de los productos elaborados en la región. A continuación, se visitaron establecimientos para la transformación y el comercio de productos forestales, como mercados, industrias y locales de venta (ver el anexo 1). En estos lugares se observaron las condiciones y dinámicas comerciales, y se realizaron entrevistas informales a vendedores, trabajadores y consumidores. Finalmente, se sostuvieron entrevistas con informantes clave del gobierno regional, industrias locales y organizaciones no gubernamentales para conocer sus percepciones sobre las características y oportunidades del mercado. En total, durante esta primera etapa se realizaron 56 entrevistas informales.

A lo largo del sondeo se analizó una gran variedad de productos forestales. Entre los productos maderables se consideraron los rubros de madera aserrada, muebles, puntales (o "pie derecho"), leña y carbón. Entre los no maderables, se analizaron productos como plantas medicinales, orquídeas, hongos comestibles, hormigas comestibles y productos derivados de fibras vegetales (ver el anexo 2).

El análisis de los resultados del sondeo permitió definir los tres productos con mayor potencial para beneficiar a los pequeños productores que en el futuro podrían aplicar a contratos CUSAF. Estos son: la madera aserrada, los puntales o "pie derecho", y la leña. En la evaluación que precedió a su elección, algunos productos no maderables fueron descartados por presentar inconvenientes que se detallan a continuación:

- Hormigas siquisapas o mamaco (Atta laevigata): Estas hormigas son valoradas por las tradiciones culinarias regionales, pero su demanda en otras regiones es limitada. Asimismo, al ser un recurso silvestre de aparición esporádica, no puede ser comercializado de manera constante.

- Hongos: Existen varias especies de hongos silvestres valorados por las tradiciones culinarias regionales (Auricularia sp. y Pleurotus ostreatus). Sin embargo, su promoción requiere de inversión adicional en investigación para su manejo. Por otro lado, estos productos no cuentan con mucha demanda fuera de la región.

- Fibras utilizadas para la elaboración de canastas: En los distritos estudiados se utilizan plantas como el bombonaje (Carludovica palmata) para tejer canastas y sombreros. Sin embargo, esta fibra se obtiene de plantas de humedales de bajura, cuya zona no se encuentra priorizada por 
el proyecto. Adicionalmente, la comercialización de las canastas producidas con esta fibra está siendo desplazada en el mercado por la de contenedores de plástico, como consecuencia de un creciente uso de los humedales para cultivos de arroz.

- Frutas: Se observó una gran variedad de frutas regionales en los mercados locales (ver el anexo 2) como aguaje (Mauritia flexuosa), inga-guaba (Inga edulis), inga-pacae (Inga sp.), inga-shimbillo (Inga sp.), morera (Morus alba) y pomarosa (Syzygium jambos). Sin embargo, los pequeños productores locales que se dedican a su venta enfrentan los riesgos de comercializar un producto altamente perecible y de bajo precio. Del mismo modo, suelen encontrarse en una posición desventajosa cuando provienen de zonas alejadas.

- Plantas medicinales: El valor agregado de las plantas medicinales extraídas por pequeños productores resultaba poco claro. Principalmente debido a que estos productos son extraídos de plantas en estado silvestre y su precio de venta en el mercado es relativamente bajo.

\subsection{Estudio de cadenas de valor forestal en Moyobamba}

La segunda etapa consistió en el análisis de las cadenas de valor de los tres productos seleccionados: la madera aserrada, el pie derecho y la leña. Su objetivo fue profundizar el análisis sobre las tres cadenas de valor e identificar los retos que enfrentan los pequeños productores que participan en ellas. Esta etapa se llevó a cabo del 4 al 21 de diciembre de 2019 en los distritos de Moyobamba, Soritor y Jepelacio, los cuales lideran la comercialización de productos forestales en la provincia. Moyobamba concentra la mayor parte de los aserraderos urbanos y puntos de venta. Por su parte, Soritor y Jepelacio son el primer y el segundo distrito con mayor comercialización de madera en la provincia, y los principales proveedores de madera en rollo y madera aserrada de la ciudad de Moyobamba.

El distrito de Soritor se ubica en el suroeste de la provincia de Moyobamba, a $22 \mathrm{~km}$ de la ciudad homónima, capital de la provincia. Es el segundo distrito con mayor superficie de la provincia y cuenta con 77 centros poblados y 21514 habitantes (INEI, 2017). Es accesible por carretera asfaltada desde la ciudad de Moyobamba hasta el centro poblado Selva Alegre, el cual se encuentra a media hora de recorrido en auto de su capital. Sus principales actividades económicas son la agricultura -especialmente el cultivo de arroz, café y cacao- y la industria maderera -principalmente para la producción de muebles-.

Jepelacio se ubica al sureste de la provincia, a $15 \mathrm{~km}$ de la ciudad de Moyobamba. Es el tercer distrito con mayor superficie de la provincia y cuenta con 83 centros poblados y 15377 habitantes (INEI, 2017). Desde la ciudad de Moyobamba se puede acceder al distrito por carretera asfaltada hasta el centro poblado Carrizales. A partir de allí, el resto de sus centros poblados son accesibles únicamente por trocha. Sus principales actividades económicas son la agricultura-especialmente el cultivo de arroz, café y caña de azúcar-y la crianza de ganado vacuno y aves de corral.

Durante esta segunda etapa de recolección de información se realizaron 48 entrevistas semiestructuradas. Los informantes fueron seleccionados mediante el método de bola de nieve, empezando por aquellos identificados durante la etapa de sondeo. Se buscó contar con representantes de los diferentes eslabones de las cadenas de valor. Por tal motivo, entre los entrevistados hubo participantes involucrados en el suministro de materia prima, los servicios relacionados con la tala, los centros de transformación, los medios de distribución y los puntos de venta; así como consumidores finales.

Las características de la muestra son presentadas en la tabla 1. Las entrevistas semiestructuradas fueron diseñadas para conocer a los actores que participan de cada uno de estos eslabones, así como sus dinámicas de trabajo, los criterios que influyen en su toma de decisiones y sus percepciones sobre las características y oportunidades del mercado. 
Tabla 1. Informantes entrevistados

\begin{tabular}{|c|c|c|c|c|c|}
\hline \multirow{2}{*}{ Actores } & & \multicolumn{4}{|c|}{ Número de informantes } \\
\hline & & Total & Moyobamba & Soritor & Jepelacio \\
\hline $\begin{array}{l}\text { Pequeños } \\
\text { productores }\end{array}$ & Madera aserrada, pie derecho, leña & 10 & 0 & 3 & 7 \\
\hline \multirow{2}{*}{$\begin{array}{l}\text { Prestadores de } \\
\text { servicios }\end{array}$} & Transportista & 1 & 1 & 0 & 0 \\
\hline & Motosierrista & 1 & 1 & 0 & 0 \\
\hline \multirow{4}{*}{$\begin{array}{l}\text { Centros de } \\
\text { transformación }\end{array}$} & Aserraderos urbanos & 4 & 4 & 0 & 0 \\
\hline & Aserraderos rurales & 2 & 0 & 2 & 0 \\
\hline & Carpinterías urbanas & 4 & 3 & 1 & 0 \\
\hline & Carpinterías rurales & 5 & 0 & 2 & 3 \\
\hline \multirow{4}{*}{$\begin{array}{l}\text { Distribuidores y } \\
\text { vendedores }\end{array}$} & Muebles & 3 & 3 & 0 & 0 \\
\hline & Leña & 5 & 4 & 1 & 0 \\
\hline & Pie derecho & 3 & 3 & 0 & 0 \\
\hline & Carbón & 2 & 2 & 0 & 0 \\
\hline \multirow{2}{*}{$\begin{array}{l}\text { Consumidores } \\
\text { finales }\end{array}$} & Leña & 5 & 4 & 1 & 0 \\
\hline & Pie derecho & 2 & 1 & 1 & 0 \\
\hline Total & & 47 & 26 & 11 & 10 \\
\hline
\end{tabular}

Durante esta etapa se entrevistaron a diez pequeños productores de los mercados de Jepelacio y Soritor ${ }^{3}$. Estos actores fueron seleccionados por contar con parcelas individuales que incluyen bosques o sistemas agroforestales. Al momento de la entrevista, ninguno contaba con título de propiedad sobre sus tierras, por lo cual, para definir los límites de sus parcelas, se basaron en derechos consuetudinarios reconocidos por acuerdos efectuados con los usuarios de los terrenos colindantes. Tres de aquellos vivían en centros poblados próximos a la capital distrital y el resto habitaba centros poblados lejanos, ubicados a cinco horas de camino a partir del punto de carretera más próximo. Dos eran oriundos de Moyobamba y el resto, migrantes provenientes de departamentos como Cajamarca, Lambayeque y Piura.

Todos los pequeños productores entrevistados describieron sus parcelas como áreas diversificadas con cultivos de café y árboles de guaba, entre otros cultivos agrícolas. Aunque varios mencionaron tener plantaciones forestales, ninguno tenía plantaciones monoculturales de árboles maderables en sus parcelas. Sin embargo, todos indicaron haber vendido árboles de sus parcelas alguna vez y señalaron que la venta de recursos forestales -principalmente los maderables encontrados en sus bosques remanentes o purmas- representa un componente importante de su economía.

En esta etapa también se realizaron entrevistas a dos grupos de prestadores de servicios, quienes trabajan de manera independiente durante las campañas de extracción de árboles. Existen distintas ocupaciones, tales como:

- Motosierristas: personas de la localidad contratadas para talar y aserrar árboles. Cuentan con equipos propios y cotizan sus honorarios por volumen aserrado.

- Transportistas: provienen del área urbana de los distritos de Moyobamba y Soritor. Cuentan con vehículos propios y cotizan sus servicios por volumen de carga y distancia.

- Cargadores, cocineras y ayudantes: viven en el caserío de donde se extraen los recursos y reciben su remuneración por jornal de trabajo.

3 Originalmente se había previsto realizar visitas a caseríos y parcelas de pequeños productores para inicios del 2020, pero ello no fue posible debido al inicio de la pandemia del COVID-19. 
Asimismo, se realizaron quince entrevistas a dueños y trabajadores de centros de transformación. Este grupo de centros de transformación incluye una diversidad de aserraderos y carpinterías con diferentes estrategias y escalas de producción. Su importancia en el mercado de madera radica en que su tecnología e infraestructura permiten dar valor agregado a los recursos maderables y satisfacer la demanda local de productos elaborados, como madera aserrada y muebles.

Fueron entrevistados cuatro dueños de aserraderos urbanos de Moyobamba y dos de aserraderos de Soritor -uno rural y uno urbano-, lo que representa un tercio del total de aserraderos del distrito. El distrito de Jepelacio no cuenta con aserraderos. Asimismo, se entrevistó a representantes de cuatro carpinterías urbanas - tres en Moyobamba y una en Soritor- y cinco carpinterías rurales - dos en Soritor y tres en Jepelacio-.

Los aserraderos urbanos son establecimientos que, en su mayoría, operan desde hace más de 20 años y se encargan de transformar los tablones en productos finales. Generalmente, cuentan con dos o tres trabajadores permanentes, aunque en contextos de gran demanda pueden contratar hasta seis trabajadores. Se caracterizan por utilizar la sierra de cinta estacionaria que permite aserrar cuartones de hasta $50 \mathrm{~cm}$ de ancho. Sus establecimientos tienen superficies de entre $1000 \mathrm{~m}^{2}$ y $1800 \mathrm{~m}^{2}$. Debido a los grandes volúmenes de madera que manejan tienden a ser más fiscalizados que el resto de actores de la cadena, por lo que requieren abastecerse de madera formal.

Por su parte, los aserraderos rurales operan en Soritor desde hace aproximadamente 5 años y abastecen a las zonas rurales. De forma eventual, también prestan el servicio de transformar la madera que es extraída de las parcelas de los pequeños productores a tablones, el formato solicitado por los aserraderos y las carpinterías urbanas. Por lo general, son informales, cuentan con dos o tres trabajadores permanentes, y utilizan equipos de aserrío portátiles con capacidad de aserrar cuartones de hasta $50 \mathrm{~cm}$ de ancho. Sus establecimientos no superan los $1000 \mathrm{~m}^{2}$ y están ubicados en áreas cercanas a los lugares de extracción que cuentan con acceso por carretera.

Mientras tanto, las carpinterías dan a la madera una transformación complementaria a la provista por los aserraderos, la cual se requiere para la fabricación de muebles o partes para muebles. En la zona rural, las carpinterías se encargan de abastecer al mercado local. No obstante, en ocasiones también venden sus productos a zonas urbanas, beneficiándose de que la fiscalización para el transporte de muebles de madera es menor que la que existe para transportar madera aserrada.

En la zona urbana, algunas carpinterías están asociadas con aserraderos. Incluso, algunos aserraderos urbanos complementan la venta de productos para el sector construcción montando carpinterías para la fabricación de muebles dentro de sus plantas, como actividad secundaria. Los muebles acabados son distribuidos en mercados locales y nacionales. Dos de los tres dueños de carpinterías entrevistados en Moyobamba mencionaron haber vendido muebles de cedro a departamentos como Lima, Arequipa, Lambayeque y Cajamarca.

Adicionalmente, tres vendedores de muebles, cuatro de leña, dos de pie derecho y dos de carbón participaron en las entrevistas. Al igual que cinco consumidores de leña y dos de pie derecho. Para ello se asistió a los principales puntos de venta. Los muebles suelen venderse en tiendas asociadas con carpinterías o en puestos en el mercado. Los pie derechos, son vendidos por distribuidores en puestos en zonas periurbanas, muchas veces junto con leña. Por su parte, los vendedores de leña suelen venderla en panaderías, restaurantes y puestos en los mercados.

En las cadenas de valor estudiadas existe un tipo adicional de actor que trabaja como intermediario y a quien se le conoce como "proveedor". Los proveedores se encargan de gestionar la extracción y el transporte de un tipo de producto hasta un centro de acopio, para posteriormente vender los ejemplares acumulados a centros urbanos de transformación y venta, quienes demandan grandes volúmenes. Existen proveedores de distintos tipos de productos forestales. Los de madera operan en la provincia desde hace aproximadamente 10 años y generalmente se abastecen de madera 
informal procedente de tierras de pequeños productores sin títulos ni permisos de aprovechamiento. No se pudo entrevistar a ningún proveedor de madera aserrada debido a que estos actores mantienen un perfil discreto; según informantes entrevistados, no suelen contar con razón social ni establecimientos definidos.

La información recopilada durante la segunda etapa sirvió para analizar las características de las cadenas de valor de los tres productos seleccionados e identificar los cuellos de botella que disminuyen su eficiencia y afectan negativamente a los pequeños productores. A continuación, se presentan los resultados de dicho análisis. 


\section{Tres cadenas de valor forestal con potencial para pequeños productores}

\subsection{Madera aserrada}

La madera aserrada, uno de los productos elegidos por el estudio, se usa para producir tablas, maderas escuadradas o muebles. Se seleccionó este producto debido a que actualmente lidera el mercado forestal en la región y cuenta con un sistema productivo funcional. Además, tiene el potencial de beneficiar a los pequeños productores de la región que en el futuro puedan aplicar a contratos CUSAF. A continuación, se describen las características de la actual cadena de valor y se identifican los aspectos en los que es necesario seguir trabajando para garantizar que en el futuro esta sea una opción sostenible y rentable para los pequeños productores con contratos de CUSAF en la región.

La cadena de valor de madera aserrada se desarrolla en seis etapas. Inicia cuando los aserraderos urbanos o los proveedores de madera comunican a sus redes de proveedores que requieren madera de determinadas especies o calidades. Esta confirmación de demanda desencadena la etapa de selección, en la que los pequeños productores identifican en sus parcelas los árboles con potencial demanda en el mercado.

Los pequeños productores seleccionan los árboles con fustes rectos de mayor diámetro y altura. Para la venta requieren de árboles con diámetros mayores a $50 \mathrm{~cm}$, aunque en ocasiones pueden comercializar algunas especies con diámetros que van de $30 \mathrm{~cm}$ a $50 \mathrm{~cm}$. Aprovechando diversas especies forestales que crecen en sus bosques remanentes, secundarios o plantaciones forestales, los pequeños productores abastecen parte significativa de la materia prima para la industria local de madera aserrada.

Los proveedores de madera la compran de los pequeños productores, generalmente como árboles en pie. Al negociar el precio se toman en cuenta la especie de árbol y el volumen estimado de madera aserrada a obtener. Por ejemplo, un árbol de madera blanda de $50 \mathrm{~cm}$ de diámetro y una altura comercial de 5 metros puede costar alrededor de 100 soles.

\footnotetext{
Un árbol de estas dimensiones puede producir 16 cuartones o 32 tablones. Dependiendo de la especie, el tablón puede ser vendido en S/24 en Moyobamba. Considerando los costos de producción y transporte, los informantes estiman que el proveedor de madera podría ganar S/198 soles por su venta, equivalente a S/6.2 por cada tablón. Posteriormente, un aserradero urbano puede transformar estos tablones en 64 tablas por un costo de $\mathrm{S} / 816$. Por la venta de cada tabla a un precio de $\mathrm{S} / 16.5$ soles, se obtendría una utilidad total de $\mathrm{S} / 240$ soles, equivalente a $\mathrm{S} / 375$ soles por cada tabla.
}

Estas cifras permiten observar que los proveedores de madera y los aserraderos urbanos pueden obtener aproximadamente el doble de ganancia que los pequeños productores. Sin embargo, también advierte que son ellos quienes asumen la mayor parte del riesgo y de la responsabilidad por el proceso productivo. Una evidencia de ello es que, mientras los pequeños productores reciben su pago el mismo día que realizan la venta, los proveedores de madera y aserraderos urbanos deben invertir un capital con miras a recibir ganancias semanas o meses después.

Tras la compra de los árboles, los proveedores de madera se encargan de gestionar su extracción, procesamiento, transporte y acopio. Anteriormente, los aserraderos urbanos se encargaban de estas tareas, pero dejaron de resultarles atractivas luego de que la Ley Forestal de 2011 causó un incremento en el nivel de fiscalización. 
Desde entonces, el liderazgo en estas actividades ha sido asumido por los proveedores de madera; un nuevo tipo de actor que se encarga de ofrecer a los aserraderos urbanos madera procesada y con documentación legal. Son ellos quienes ahora asumen el riesgo financiero de estas tareas, gestionan su logística y contratan a los prestadores de servicios necesarios para su ejecución, como motosierristas, ayudantes y transportistas.

En la primera transformación, los árboles son cortados en cuartones en la misma parcela en la que han sido extraídos. Cada árbol es talado, desramado y trozado en piezas rollizas llamadas trozas. Luego, el motosierrista lo transforma en cuartones, que son segmentos de madera escuadrada con las siguientes características:

- Cuatro aristas, $25 \mathrm{~cm}$ de ancho y $10 \mathrm{~cm}$ de espesor.

- Longitudes de 2,50 m, de 3,0 m, o de 5,0 m.

- Volúmenes de aproximadamente $0,06 \mathrm{~m}^{3} ; 0,07 \mathrm{~m}^{3} ; \mathrm{y} 0,12 \mathrm{~m}^{3}$.

Los motosierristas producen los cuartones en el sitio de tala usando sus motosierras. Sin embargo, ocasionalmente, usan la herramienta castillo o chulla chaqui. El chulla chaqui es una herramienta con dos motores de motosierra y un marco guía que permite lograr un corte más uniforme sobre la madera.

Una vez que la madera ha sido convertida en cuartones, estos son extraídos del bosque en dirección al camino vial más cercano. Cuando es necesario, se abren trochas para su traslado. En el proceso de transporte, los cuartones son halados por animales de carga, como mulas y caballos, para ser luego trasladados en camiones hasta un aserradero rural (ver la figura 1).

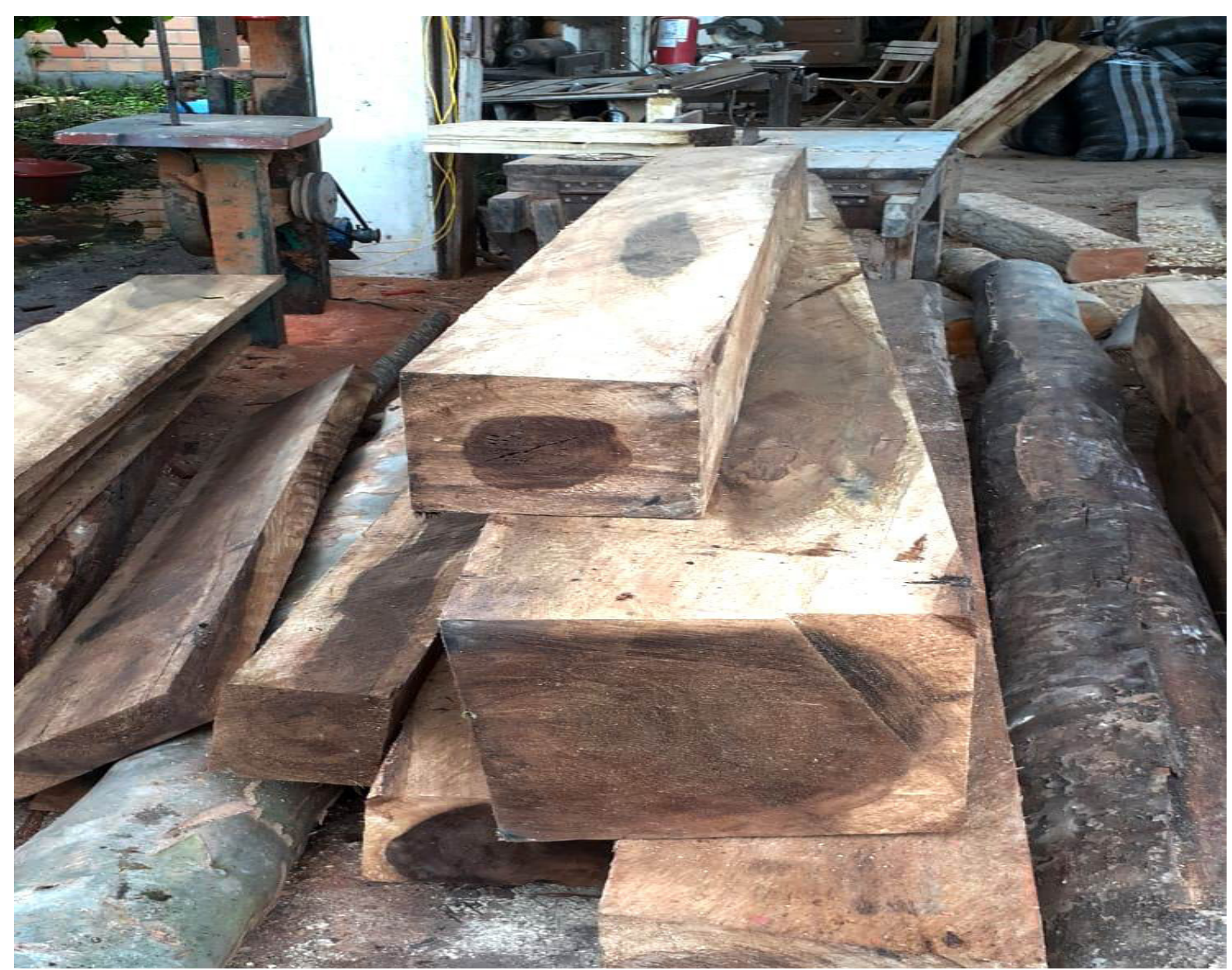

Figura 1. Cuartones apilados en aserradero rural en el distrito de Soritor, provincia de Moyobamba. Fuente: CIFOR 
En los aserraderos rurales de Soritor o en las carpinterías rurales de Jepelacio se procesa por segunda vez la madera al convertir los cuartones en tablones. Un tablón se obtiene al aserrar por la mitad, de forma longitudinal, un cuartón. De esta manera, se conserva el ancho de la pieza y por cada cuartón se obtienen dos tablones.

Posteriormente, los tablones son transportados a un centro de acopio donde son almacenados y puestos a secar. El proceso de secado reduce la humedad de la madera con el fin de aminorar su peso, darle estabilidad dimensional, aumentar su resistencia mecánica, disminuir su susceptibilidad al ataque de hongos o pudrición y facilitar posteriores manipulaciones de la madera. Generalmente, se realiza al aire libre, apilando las maderas; aunque, para acelerar el proceso, también se puede realizar por medio de hornos. Al aire libre el secado tarda de uno a tres meses; en horno, tarda de una a tres semanas.

Tanto las localidades de Moyobamba como Soritor cuentan con un aserradero con horno de secado. El de Moyobamba es una cabina metálica cerrada, con una capacidad de aproximadamente $2 \mathrm{~m}^{3}$. En la parte externa tiene una cabina de combustión que utiliza los restos de madera de aserrío. Asimismo, cuenta con tuberías que inyectan vapor de agua al interior, y un medidor de temperatura y humedad.

Durante el periodo de secado, los proveedores de madera negocian la venta de los tablones con aserraderos urbanos y consiguen documentos formales para evitar la incautación durante su transporte hacia el aserradero urbano. De esta manera, logran introducir madera informal (o sea, ilegal) al mercado formal; modalidad denominada por los informantes como "blanqueo de la madera".

Pese a que el grueso de la madera comercializada por los proveedores de madera proviene de tierras de pequeños productores sin títulos ni permisos de aprovechamiento; en ocasiones estos actores también comercializan madera de procedencia legal, proveniente de comunidades nativas o concesiones forestales.

Recientemente, pequeños aserraderos y carpinterías ubicados en centros poblados menores han decidido gestionar de forma autónoma el acopio de tablones y su venta y transporte a aserraderos urbanos, compitiendo así con los proveedores de madera. Los pequeños productores pueden optar por vender sus maderas a estos aserraderos o carpinterías rurales, una inversión que les resulta rentable.

Para vender sus productos por este medio, los pequeños productores deben invertir en la contratación de motosierristas y transportistas, y en el alquiler de mulas. Un pequeño productor invertiría un estimado de $S / 270$ soles para producir 16 cuartones, los cuales podría vender a S/30 soles cada uno, generando una ganancia de $\mathrm{S} / 210$ soles.

Tras el secado de la madera, los proveedores de madera -o los aserraderos y carpinterías ruralesvenden los tablones a una diversidad de aserraderos y carpinterías urbanas. Estas tienen diferentes estrategias y escalas de producción, y se encargan de transformar los tablones en productos finales como madera escuadrada, tablas, horcones, vigas y listones (ver la tabla 2).

Actualmente, los aserraderos urbanos son los actores más influyentes de esta cadena de valor pues concentran la maquinaria y tecnología para la transformación final, y son los únicos con capacidad de producir los volúmenes que demandan los proyectos de construcción. Las carpinterías también juegan un rol importante en la rama de la cadena dedicada a producir muebles pues usan su tecnología para agregar valor a los productos y satisfacer la demanda del mercado.

Analizada en su conjunto, la producción de madera aserrada cuenta con una cadena de valor establecida y operativa en los distritos estudiados, además de representar un aporte importante a la economía local. Sin embargo, el potencial de esta cadena actualmente es mermado por un conjunto de lastres, entre los que resaltan su informalidad y la necesidad de realizar reformas en beneficio de los pequeños productores. 
Tabla 2. Productos más vendidos por los aserraderos urbanos

\begin{tabular}{lll}
\hline Producto & Uso & Dimensiones \\
\hline Tablas & $\begin{array}{l}\text { Para encofrados (armazón para moldear el } \\
\text { cemento) }\end{array}$ & $3,8 \mathrm{~cm} \times 25,4 \mathrm{~cm} \times 3,5 \mathrm{~m}^{\mathrm{b}}$. \\
\hline Horcones & Como soporte de estructuras. & $10 \mathrm{~cm} \times 10 \mathrm{~cm} \times 2,5 \mathrm{~m}$ (o en algunos casos \\
& & $3 \mathrm{~m}$ o $5 \mathrm{~m}$ ). \\
\hline Vigas & Como soporte para techos de inmuebles. & $\begin{array}{l}\text { Espesor: } 5 \mathrm{~cm} \times 25 \mathrm{~cm} \times 2,5 \mathrm{~m} \text { (o en algunos } \\
\text { casos } 3 \mathrm{~m} \mathrm{o} 5 \mathrm{~m} \text { ) }\end{array}$ \\
\hline \multirow{2}{*}{ Listones } & En uniones o tijerales para el soporte de & $5 \mathrm{~cm} \times 5 \mathrm{~cm}$. \\
& estructuras. & Existen en diversas longitudes.
\end{tabular}

\section{Notas:}

a Informantes relacionados con los aserraderos urbanos mencionaron que para obras grandes, como la construcción de carreteras o de inmuebles de gran tamaño, se utiliza madera producida en Loreto y Pucallpa, debido a que en estas regiones se puede conseguir madera de dimensiones mayores $(3.8 \mathrm{~cm} \times 50 \mathrm{~cm} \times 7.6 \mathrm{~m}$ ) y especies que no son disponibles cerca de Moyobamba.

b Convencionalmente, el sector utiliza unidades imperiales en vez del sistema métrico. En esa unidad de medida, las tablas son de $1.5^{\prime \prime} \times 10^{\prime \prime} \times 10^{\prime \prime}$.

Siendo actores clave en la cadena de valor -al proveer la mayor parte de su materia prima-, los pequeños productores participan de esta cadena en condiciones desfavorables. La falta de títulos de propiedad y permisos de aprovechamiento les impide comercializar la madera legalmente. Sin estos documentos, dependen de intermediarios para vender sus productos, lo que los coloca en una posición desventajosa al negociar los precios. Asimismo, limita sus posibilidades de diversificar sus ingresos involucrándose en etapas de la cadena posteriores a la tala del árbol.

Otro lastre de la cadena es el uso de prácticas poco sostenibles de manejo forestal. Actualmente, la sobreexplotación de las especies de madera con mayor demanda en el mercado -como el cedro, la capirona o el tornillo- amenazan la sostenibilidad de la cadena en el tiempo. El aprovechamiento poco sostenible de ciertas especies se traduce en su escasez, la degradación de los bosques remanentes y su consecuente pérdida de biodiversidad y potencial económico.

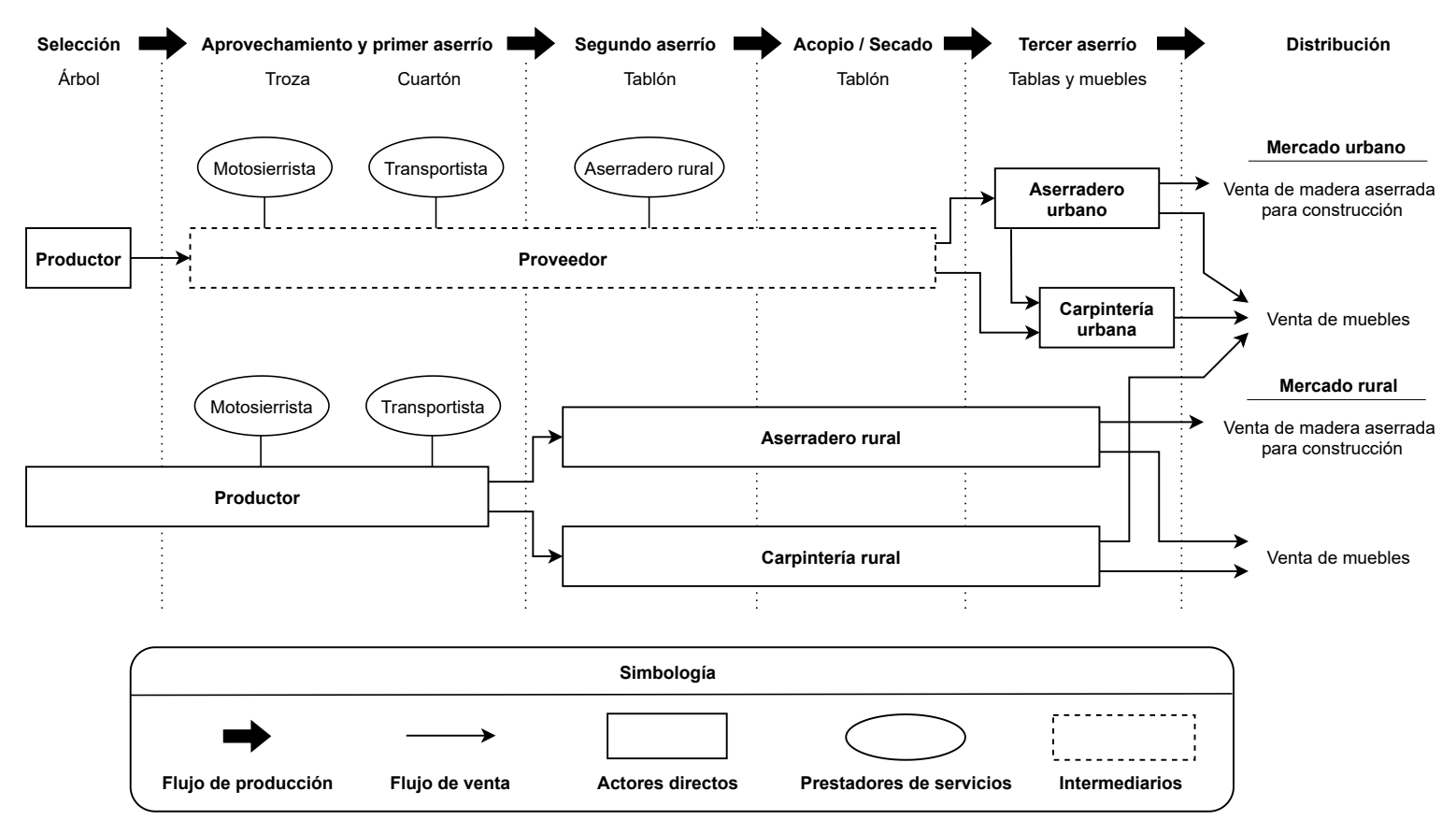

Figura 2. Cadena de valor de madera aserrada 
Tomando en cuenta estos cuellos de botella, consideramos necesaria la implementación de reformas. Solo así se podrá consolidar la producción de madera aserrada como una actividad sostenible y rentable para los pequeños productores que en el futuro puedan acceder a contratos de CUSAF. Estas reformas deben apuntar a mejorar las prácticas de manejo, dotar a los pequeños productores de condiciones que les permitan participar legalmente de la cadena, e incrementar los beneficios que obtienen por su participación.

Actualmente, la cadena cuenta con un amplio potencial de mejora. Por ejemplo, la implementación de sistemas agroforestales y plantaciones convencionales podría contribuir a incrementar la productividad de los pequeños productores, dentro de una propuesta formal y sostenible. Asimismo -como veremos en la próxima sección-, es necesario mejorar el acceso de los pequeños productores a información sobre: prácticas sostenibles de manejo y potenciales usos de especies subutilizadas.

\section{Especies utilizadas}

En la cadena de valor de madera aserrada se utilizan diversas especies de madera. Para calcular su valor se toman en cuenta los siguientes criterios:

- Su tiempo de vida útil, el cual varía dependiendo de qué tan susceptible es la madera a ser atacada por plagas.

- Su facilidad para trabajar con ella, la cual se determina en función de su dureza y nivel de abrasividad.

- Su estructura o capacidad de conservar la forma durante el uso, evitando torceduras o encorvaduras.

- Su disponibilidad, es decir, qué tan fácil o difícil es conseguirla en la región.

- Su veteado, compuesto por las figuras que resultan de los anillos de crecimiento del árbol o del crecimiento discontinuo de sus fibras. Estas dan un aspecto decorativo a la madera incrementando su valor en el mercado, especialmente en la industria de fabricación de muebles.

Adicionalmente se consideran sus propiedades y cómo estas condicionan su uso e influyen en la cadena productiva. Según los informantes, las maderas blandas son fáciles de trabajar, tienen una estructura uniforme y son altamente disponibles en los bosques locales, pero tienen un menor tiempo de vida útil. Por otra parte, las maderas duras tienen un mayor tiempo de vida útil y una estructura uniforme altamente valorada, pero aserrarlas involucra un mayor desgaste de los equipos de corte, lo que incrementa los costos de producción.

En los distritos analizados, los informantes reportaron que se usan de manera predominante ocho especies de madera para producir madera aserrada para el sector construcción y para la fabricación de muebles. La tabla a continuación detalla sus principales características.

De estas especies, el cedro es la más valorada en el mercado por su excelente veteado y facilidad para trabajarla. En efecto, los muebles elaborados con esta madera son los más caros del mercado. Lamentablemente, ello ha dado incentivos para su sobreexplotación y actualmente quedan pocos ejemplares de esta especie en los bosques locales. Incluso se ha incluido al cedro en la lista de especies amenazadas de la $\mathrm{CITES}^{4}$, lo que resalta la urgencia de tomar medidas que garanticen su recuperación y manejo sostenible.

Por el contrario, el laurel actualmente es una especie subutilizada. Destaca por contar con buen veteado y por ser aprovechable desde los 10 años. Sin embargo, sus propiedades son desconocidas por los consumidores locales, lo que genera que su demanda en el mercado sea baja. Para cambiar esta situación es necesario informar a productores y consumidores sobre sus potenciales usos. Ello contribuiría a diversificar las especies utilizadas en el mercado y a aliviar la presión sobre las especies que actualmente son sobreexplotadas.

4 Convención sobre el Comercio Internacional de Especies Amenazadas de Fauna y Flora Silvestres. 
Tabla 3. Especies de madera blanda más utilizadas para producir madera aserrada para construcción y muebles

\begin{tabular}{|c|c|c|c|}
\hline Especie & Usos y variedades & Ubicación & Tipo de suelo requerido \\
\hline Moena & $\begin{array}{l}\text { Para construcción: } \\
\text { - Urco moena (Ocotea } \\
\text { minutiflora) } \\
\text { - Casha moena (Ocotea sp.) } \\
\text { - Canela moena (Ocotea } \\
\text { aciphylla) } \\
\text { Para fabricar muebles: } \\
\text { - Moena amarilla } \\
\text { - Casha moena } \\
\text { - Moena colorada (Nectandra } \\
\quad \text { Longolifolia) }\end{array}$ & $\begin{array}{l}\text { - } \text { Bosques } \\
\text { secundarios } \\
\text { - } \text { Bosques } \\
\text { remanentes }\end{array}$ & $\begin{array}{l}\text { - Bien drenados } \\
\text { - Baja pedregosidad. } \\
\text { - Mayormente hasta los } 1200 \mathrm{msnm}^{\mathrm{a}}\end{array}$ \\
\hline Cumala & $\begin{array}{l}\text { Para tablas de construcción, } \\
\text { muebles y palos de escoba. }\end{array}$ & $\begin{array}{l}\text { - } \text { Bosques } \\
\text { secundarios }\end{array}$ & $\begin{array}{l}\text { - Bien drenados } \\
\text { - Pluviosidad elevada y constante } \\
\text { - Entre los } 80 \text { y } 1000 \mathrm{msnm}^{b}\end{array}$ \\
\hline $\begin{array}{l}\text { Ojé } \\
\text { blanco }\end{array}$ & Para tablas de construcción. & $\begin{array}{l}\text { - } \text { Bosques } \\
\text { remanentes }\end{array}$ & $\begin{array}{l}\text { - Terrenos aluviales periódicamente } \\
\text { inundados }{ }^{c}\end{array}$ \\
\hline Cedro & $\begin{array}{l}\text { Para muebles: } \\
\text { - } \quad \text { Cedro rosado (Cedrela sp) } \\
\text { - } \quad \text { Cedro lila (Cedrela montana) } \\
\text { - } \quad \text { Cedro huasca (Cedrela sp.) }\end{array}$ & $\begin{array}{l}\text { - Bosques } \\
\text { relictos } \\
\text { (fuentes } \\
\text { informales de } \\
\text { madera) }\end{array}$ & $\begin{array}{l}\text { - Suelos arcillosos } \\
\text { - Suelos pantanosos } \\
\text { - Llanuras inundadas durante la época } \\
\text { de lluvias }\end{array}$ \\
\hline Laurel & $\begin{array}{l}\text { Para madera aserrada y } \\
\text { muebles. }\end{array}$ & & $\begin{array}{l}\text { - En una gran variedad de suelos: } \\
\text { desde arenosos infértiles hasta rojos } \\
\text { arcillosos. } \\
\text { - En alturas por debajo de los } \\
1200 \mathrm{msnm}^{\mathrm{e}} \text {. }\end{array}$ \\
\hline
\end{tabular}

\section{Notas:}

a Reynel, C., Pennington, T.D., Flores, C. y Daza, A. (2003). Árboles útiles de la Amazonía Peruana y sus usos. Lima.

b íbidem.

c Confederación Peruana de la Madera (2008). Compendio de información técnica de 32 especies forestales, Tomo I y II. Lima: Edición CITE madera. Derechos Reservados.

d Íbidem.

e Centro Agronómico Tropical de Investigación y Enseñanza, CATIE. (1994). Laurel, Cordia alliodora (Ruiz y Pavón) Oken, especie de árbol de uso múltiple en América Central. 41 pp.

Entre las especies de madera dura, la capirona y el tornillo escasean en los bosques locales. Ello se debe a la sobreexplotación de estas especies, falta de reposición y -en el caso del tornillo- a la manipulación de sus árboles semilleros. Este no es el caso del eucalipto, especie que, por el contrario, existe en grandes cantidades.

En los últimos años, el gobierno regional ha impulsado la plantación de capirona y eucalipto, especialmente en los márgenes de las carreteras de Jepelacio y Soritor, lo que favorece la existencia de estas especies localmente. También hemos sido informados de la existencia de algunas plantaciones de tornillo en Soritor a cargo de pequeños productores. En el futuro, estas plantaciones deben de ser complementadas con medidas que promuevan el manejo de estas especies para alcanzar los estándares esperados de calidad. 
Tabla 4. Especies de madera dura más utilizadas para producir madera aserrada para construcción y muebles

\begin{tabular}{|c|c|c|c|}
\hline Especie & Usos y variedades & Ubicación & Tipo de suelo requerido \\
\hline Capirona & $\begin{array}{l}\text { Para madera aserrada y pie } \\
\text { derecho. }\end{array}$ & 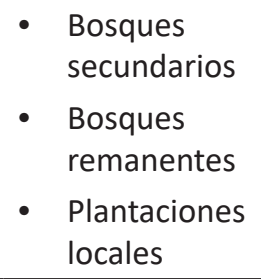 & $\begin{array}{l}\text { Terrenos periódicamente inundables, } \\
\text { incluyendo bosques ribereños }{ }^{a}\end{array}$ \\
\hline Eucalipto & $\begin{array}{l}\text { Para madera aserrada, muebles } \\
\text { (principalmente tendidos de } \\
\text { camas) y pie derecho: } \\
\text { - Eucalipto torrellana } \\
\quad \text { (Eucalyptus torreliano) } \\
\text { - Eucalipto Salinas (Eucalyptus } \\
\text { salignas) }\end{array}$ & - Plantaciones & \\
\hline Tornillo & Para muebles & $\begin{array}{ll}\text { - } & \text { Bosques } \\
\text { remanentes } \\
\text { - } \\
\text { Plantaciones } \\
\text { locales }\end{array}$ & $\begin{array}{l}\text { - } \text { Bosques de colina } \\
\text { - } \quad \text { Terrenos arcillosos } \\
\text { - } \text { pantanos. } \\
\text { - Cerca de fuentes de agua }{ }^{b}\end{array}$ \\
\hline
\end{tabular}

\section{Notas:}

a Reynel, C., Pennington, T.D., Flores, C. y Daza, A. (2003). Árboles útiles de la Amazonía Peruana y sus usos. Lima

b Freitas Da Silva, M., Medeiros, L., y Angélica de Lima, C. (1992). Leguminosas da Amazônia brasileira - II Cedrelinga Ducke (Leg. Mimos.). Belém.

Según informantes locales, el eucalipto y el tornillo a menudo se procesan de manera inadecuada. El eucalipto es secado con tecnología rústica y procedimientos inadecuados. En ocasiones, ello genera que la madera se tuerza y quede inutilizable. Por su parte, los centros de transformación mencionaron que la madera proveniente de las plantaciones de Tornillo suele presentar secciones con fibras no uniformes (conocidas con el término local "champoso"), posiblemente a consecuencia de deficiencias en el manejo de los árboles.

Adicionalmente a las ocho especies mencionadas, existen otras fuentes alternativas de especies maderables que también se utilizan en la producción de madera aserrada, aunque en menor medida. El pino chuncho (Parkia velutina Benoist), el renaco (Ficus sp.), el ushunquiro (Buchenavia sp.) y el sapote quiro (sin identificar), son especies de madera blanda que también se utilizan, así como las maderas duras del guayacán (Tabebuia chrysantha), rifari (Miconia sp.) y huacapú (Minquartia sp.). Estas especies son poco utilizadas debido a que su sobreexplotación en años anteriores ha llevado a que actualmente escaseen en los bosques locales.

\subsection{Pie derecho}

El pie derecho o puntal es otro producto seleccionado por tener el potencial de beneficiar a los pequeños productores de la región que en el futuro puedan aplicar a contratos de CUSAF. Se trata de madera rolliza de diámetros pequeños, de $10 \mathrm{~cm}$ a $15 \mathrm{~cm}$, cortada en longitudes de tres y seis metros (ver la figura 3). Generalmente, se usan en construcción de inmuebles como soportes o en la elaboración de encofrados para techos. En ocasiones, también son utilizados como horcones o columnas de casas, mayoritariamente en viviendas rurales. 


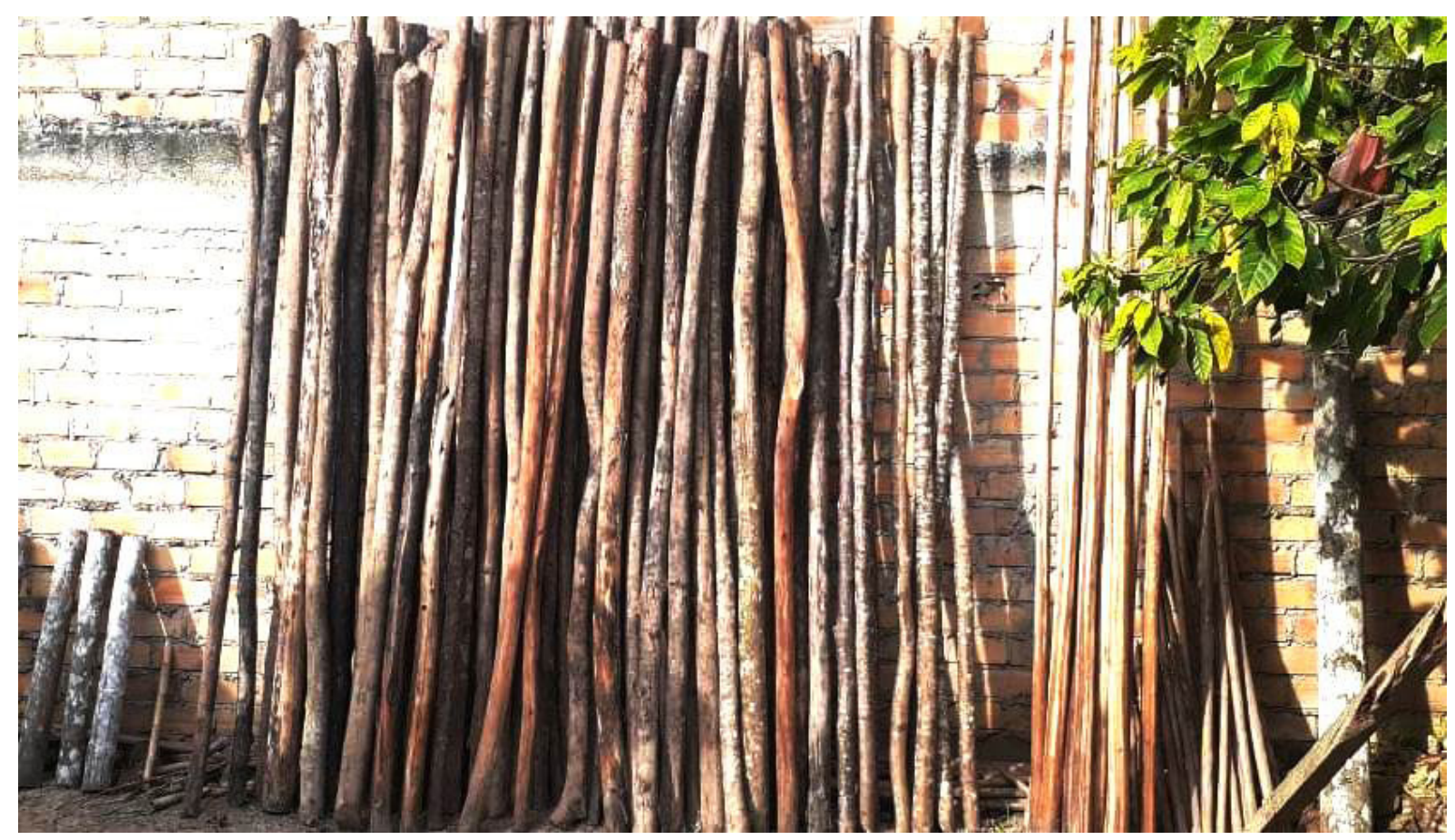

Figura 3. Puesto de venta de pie derechos en Tarapoto, San Martín.

Fuente: CIFOR

A continuación, se describen las principales características de su actual cadena de valor en la región y se indican los factores que obstaculizan la participación de los pequeños productores en ella.

A diferencia de lo que sucede en la cadena de valor de madera aserrada, en esta cadena no participan proveedores. Sin embargo, los pequeños productores también dependen de intermediarios. Pese a que el proceso productivo de esta cadena es bastante más sencillo que el de la madera aserrada, los pequeños productores no cuentan con las condiciones para vender sus productos directamente. Ello se debe principalmente a que carecen de los volúmenes necesarios para poder comercializarlos directamente con sus consumidores finales. Aun pudiendo hacerlo, esto requeriría transportarlos al área urbana, lo que supone una gran dificultad debido a que suelen carecer de los permisos necesarios para su transporte legal, entre otras razones. De igual forma, carecen de información suficiente sobre cómo funciona el mercado; no conocen a los compradores finales ni las cantidades del producto que requieren.

Por ese motivo, son los distribuidores quienes lideran esta cadena de valor. Se trata de comerciantes itinerantes que se encargan de gestionar la producción, acopio y venta del producto en función de la demanda de sus consumidores finales. Ellos recaudan los volúmenes necesarios para su venta comprando pequeñas cantidades del producto en múltiples predios rurales. Asimismo, se responsabilizan de la logística para su producción y transporte.

Los distribuidores mantienen redes de contacto con los caseríos para informarles sobre las fechas en las que visitarán la zona en busca de pie derechos. Su anuncio desencadena la etapa de selección, en la que los pequeños productores eligen las maderas que destinarán a elaborar estos productos. Estas deben provenir de árboles juveniles, de entre $10 \mathrm{~cm}$ y $15 \mathrm{~cm}$ de diámetro, con una longitud de tres a seis metros.

Generalmente, la materia prima para elaborar pie derecho se encuentra en los barbechos de crecimiento secundario, purmas -tierras agrícolas en descanso-, o en los residuos del raleo de plantaciones. En raras ocasiones se obtienen de bosques remanentes o bosques relictos, debido a que estos espacios no suelen contar con las especies apropiadas para tal fin. 
Las purmas suelen contar con una o dos especies que los pequeños productores utilizan con más frecuencia como insumo de pie derechos, debido a su alta capacidad regenerativa. Algunos productores facilitan su reproducción de manera activa, seleccionando árboles grandes como semilleros, generalmente en las orillas de los ríos. De esta forma procuran la disponibilidad de este recurso en el futuro.

Uno de los principales atractivos de esta cadena para los pequeños productores es que les permite comerciar recursos que de otra forma serían desaprovechados. Se puede producir pie derechos con subproductos de otras actividades productivas, como de los restos del raleo de plantaciones. De esta manera, los pequeños productores pueden complementar sus ingresos sin requerir inversiones adicionales.

En ocasiones, los distribuidores compran los pie derechos como producto finalizado y, en otras, como árboles en pie. En el segundo caso, se encargan de contratar motosierristas para talar los árboles y transformarlos en pie derechos por medio del uso de motosierras, hachas o machetes. Los motosierristas talan el árbol y lo trozan en longitudes de tres o seis metros, descartando las secciones que presentan deformaciones o nudos. Los pequeños productores negocian los precios de venta directamente con los distribuidores y pueden participar de la cosecha para incrementar su retribución.

Con los pie derechos fabricados, el distribuidor contrata transportistas para llevarlos a centros de acopio, ya sea por tierra o por río. Estos centros de acopio se encuentran mayormente en zonas periurbanas, donde son más accesibles a sus consumidores. La mayoría se dedica exclusivamente a la venta de pie derechos, aunque algunos la complementan con la venta de leña o caña brava. Generalmente, cuentan con permisos municipales para su funcionamiento comercial, pero carecen de documentos que aseguren la formalidad del origen de su madera o permitan su trazabilidad.

Los principales consumidores de estos productos son albañiles dedicados a la construcción de viviendas u otros inmuebles de pequeña escala. Según indican los distribuidores entrevistados, una sola venta puede requerir entre 300 y 500 pies derechos a un precio unitario que varía entre los 3 y 10 soles. Al respecto, los dos albañiles entrevistados indicaron que necesitan 150 pies derechos por cada $100 \mathrm{~m}^{2}$ de techo a construir. Anteriormente las empresas constructoras de gran escala eran las principales consumidoras de este producto, pero últimamente han disminuido su demanda por la preferencia de los pie derechos de metal, cuyo precio unitario varía entre los 80 y 110 soles.

Todos los pequeños productores entrevistados en el marco del estudio mencionaron haber vendido, al menos una vez, pie derechos o árboles para su fabricación. En esas ocasiones, el precio unitario obtenido solía ser bajo, pero el volumen de la transacción podía alcanzar niveles atractivos. Una purma contiene muchos árboles y talarlos es parte del procedimiento rutinario para cultivar la tierra, por lo que la venta de pie derechos resulta atractiva a los pequeños productores ya que no requiere de inversión, no implica riesgo y permite lucrar de recursos que se regeneran naturalmente o de residuos que de otro modo serían desechados.

En líneas generales, la producción de pie derechos es una actividad muy atractiva para los pequeños productores. Sin embargo, actualmente ellos ocupan una posición de dependencia que limita sus posibilidades de obtener mayores beneficios. Para superar esta limitante, es necesario trabajar para que cuenten con información suficiente sobre las características del mercado, puedan participar de este formalmente y desarrollen la capacidad de asumir los retos logísticos del transporte, acopio y venta de los productos. 

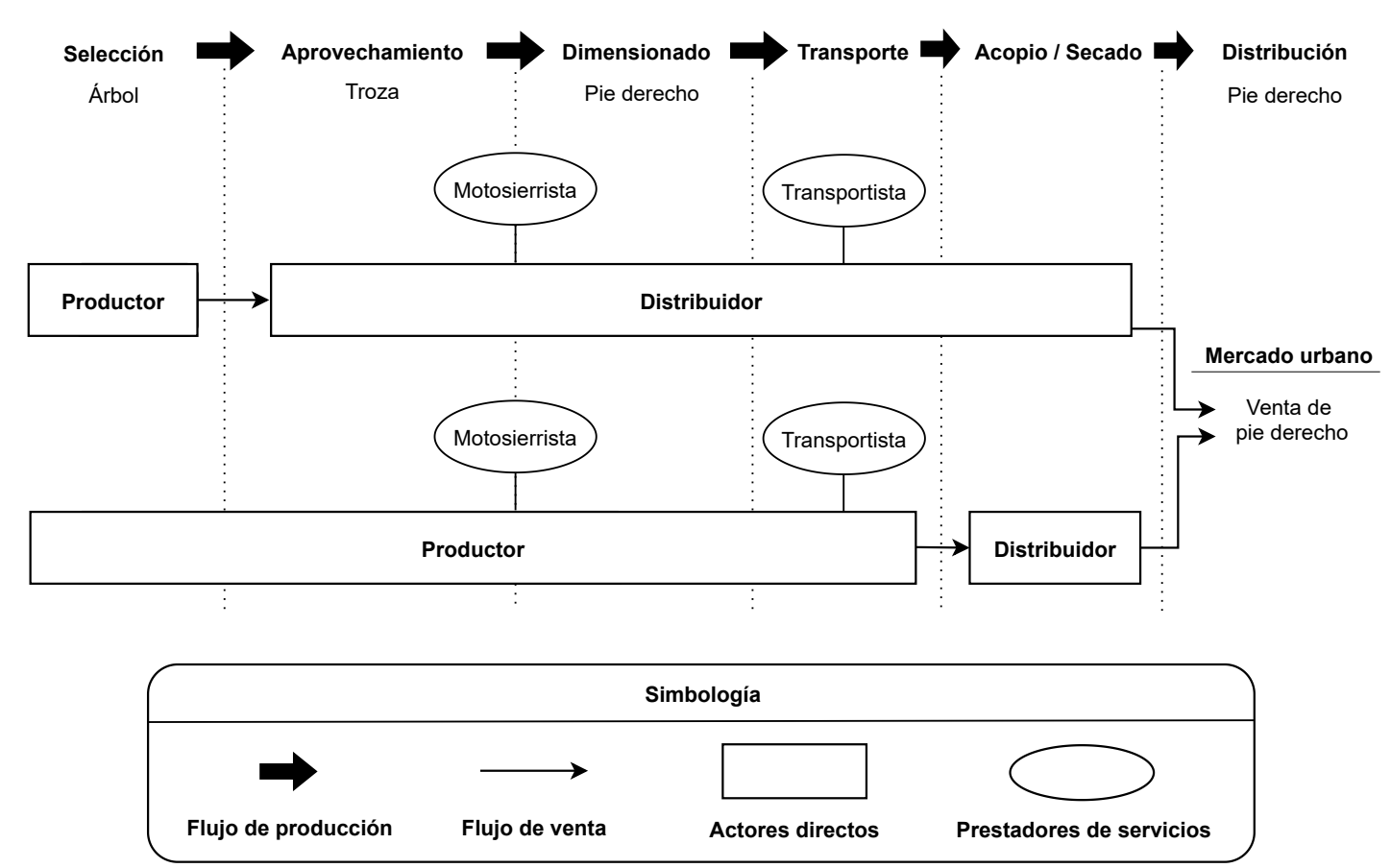

Figura 4. Cadena de valor del pie derecho

\section{Especies utilizadas}

Las especies de madera utilizadas para elaborar pie derecho son seleccionadas en función de la resistencia de la madera, que se traduce en la capacidad que tendrá el producto para soportar cargas; y de la forma de su fuste, que define su nivel de estabilidad. Ambos criterios determinan el tiempo de vida del producto y, por lo tanto, definen su valor. Adicionalmente, las especies se eligen en función de su disponibilidad en los bosques locales. Generalmente, los consumidores solicitan que los grandes volúmenes de pie derechos que compran provengan de una única especie, buscando recibir ejemplares con características similares.

Las especies de madera blanda tienen una resistencia baja, por lo que producen pie derechos que pueden ser utilizados dos veces como máximo, motivo por el cual suelen tener un precio bajo en el mercado. A pesar de ello, son vendidos con frecuencia debido a que estas especies existen en abundancia en las purmas locales. Por el contrario, las maderas duras tienen mayor resistencia y sus productos pueden reutilizarse hasta cinco veces, por lo que su precio de mercado es mayor. Aunque la disponibilidad de estas especies en los bosques locales es baja, pueden obtenerse como un subproducto del raleo de plantaciones.

La siguiente tabla detalla las características de las principales especies de madera utilizadas para producir pie derecho en la región.

Tabla 5. Especies de madera blanda más utilizadas para producir pie derecho

\begin{tabular}{|c|c|c|}
\hline Especie & Ubicación & Características \\
\hline \multirow[t]{2}{*}{$\begin{array}{l}\text { Bolaina (Guazuma crinita } \\
\text { C. Martius) }\end{array}$} & Purmas cercanas a corrientes de agua & $\begin{array}{l}\text { - Existe en gran abundancia en los } \\
\text { bosques locales. }\end{array}$ \\
\hline & & - Aprovechable desde los 5 años. \\
\hline \multirow[t]{2}{*}{$\begin{array}{l}\text { Pájaro bobo (Tessaria } \\
\text { integrifolia) }\end{array}$} & Purmas cercanas a corrientes de agua & $\begin{array}{l}\text { - Existe en gran abundancia en los } \\
\text { bosques locales. }\end{array}$ \\
\hline & & - $\quad$ Aprovechable desde los 4 años. \\
\hline
\end{tabular}


Tabla 6. Especies de madera dura más utilizadas para producir pie derecho

\begin{tabular}{lll}
\hline Especie & Ubicación & Características \\
\hline Eucalipto (Eucalyptus sp.) & Plantaciones & \\
\hline $\begin{array}{l}\text { Capirona (Calycophyllum } \\
\text { spruceanum) }\end{array}$ & Plantaciones & $\begin{array}{l}\text { Los pequeños productores } \\
\text { entrevistados indicaron que estas } \\
\text { plantaciones no se encuentran en sus } \\
\text { parcelas, sino en los márgenes de la } \\
\text { carretera de Moyobamba a Soritor, } \\
\text { donde tienen más accesibilidad. }\end{array}$ \\
\hline $\begin{array}{l}\text { Uriamba (Miconia sp.) } \\
\text { glandulosa) }\end{array}$ & Bosques secundarios & \\
\hline
\end{tabular}

En los últimos años, en la región se ha empezado a utilizar bambú para producir pie derechos. El bambú es una especie no maderable que se caracteriza por su estructura recta y su gran resistencia, igual o mayor a la de las maderas duras, así como por su rápido crecimiento; según los comerciantes entrevistados, se puede producir pies derechos de esta especie con una altura de 6 metros en tan solo tres años, y de 20 metros, en diez años. Sin embargo, pese a sus potencialidades y a que existen especies nativas de bambú leñoso en la región; en la actualidad el uso de esta especie para elaborar pie derecho continúa siendo impopular entre los pequeños productores.

\subsection{Leña}

El siguiente producto identificado por tener potencial de beneficiar a los pequeños productores de la región es la leña. Este producto es utilizado como combustible en hogares y negocios de comida. Consiste en porciones quebradas o rajadas de madera, obtenidas de la roza o raleo de purmas, el raleo de plantaciones y sistemas agroforestales; o de los residuos de árboles extraídos para otros fines (ver la figura 5). A continuación se describen las principales características de esta cadena de valor y se identifican los factores que requieren ser atendidos para fortalecer la participación de los pequeños productores en ella.

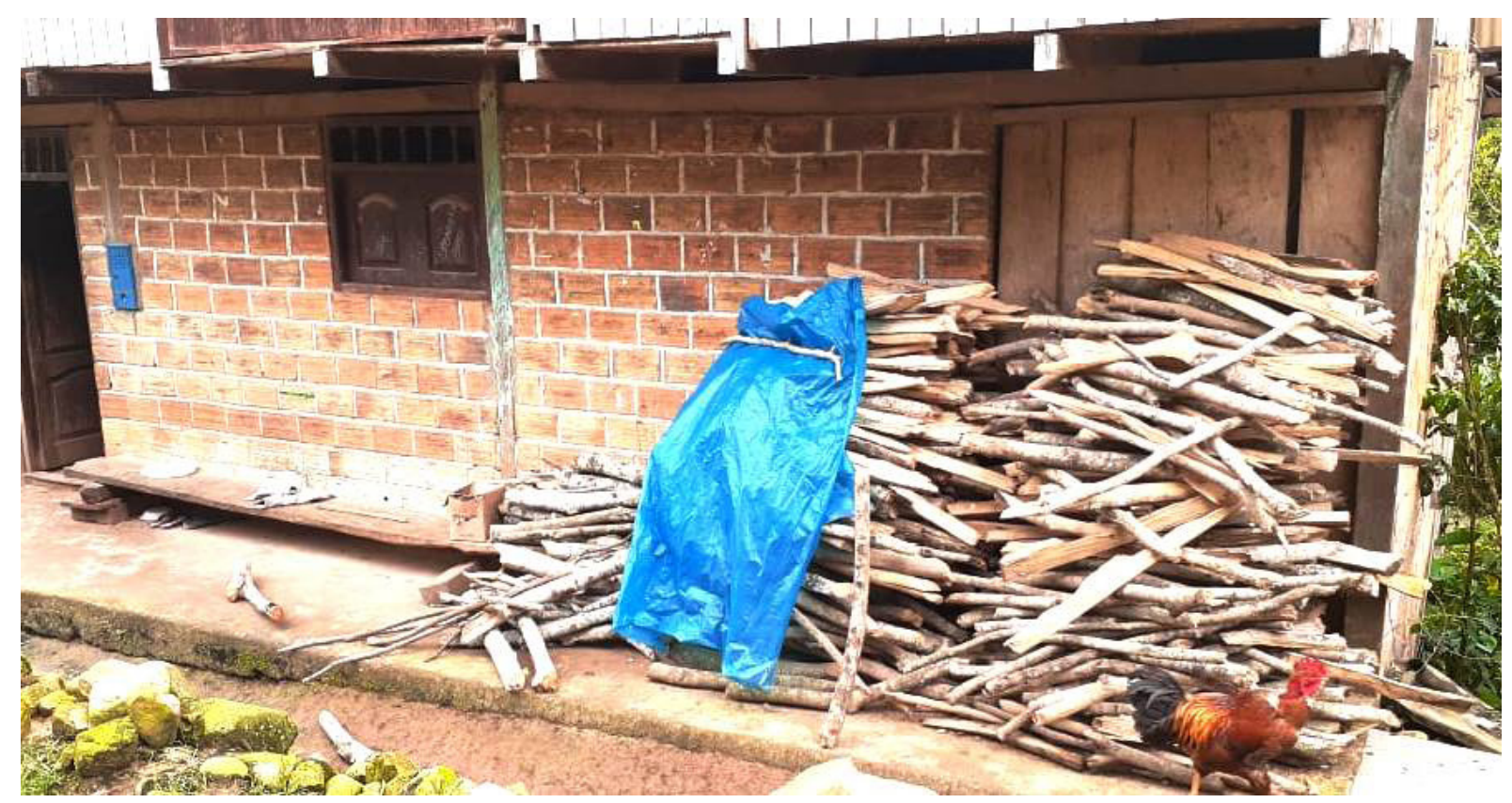

Figura 5. Leña apilada en vivienda y disponible para su venta en el distrito de Jepelacio, San Martín. Fuente: CIFOR 
Como sucede en la cadena de valor de pie derecho, en esta cadena los pequeños productores dependen de la intermediación de distribuidores para vender sus productos. Ello se debe a la ausencia de mecanismos legales para esta actividad. Además, no cuentan con las redes necesarias ni la capacidad logística para vender su leña directamente a los consumidores finales.

En esta cadena, los distribuidores pueden ser mayoristas o minoristas. Los primeros se encargan de gestionar la compra de pequeñas cantidades de leña que ofrecen los pequeños productores, transportarla a zonas urbanas y almacenarla hasta reunir los volúmenes necesarios para su comercialización. Asimismo, abastecen la demanda de los productores de cecina y de pan, quienes requieren grandes cantidades del producto cada semana.

Los distribuidores minoristas abastecen al mercado para los consumidores que requieren el producto en escalas pequeñas, como combustible en hogares urbanos. Estos distribuidores no cuentan con medios de transporte ni equipos de aprovechamiento, por lo que no participan de las tareas de transformación y secado. Por el contrario, se enfocan en comprar y revender la leña de los productores en el mercado urbano.

El ciclo productivo de esta cadena generalmente inicia cuando el distribuidor mayorista recibe un pedido de leña, frecuentemente con volúmenes y calidades específicas, y coordina su compra con pequeños productores en zonas rurales. Ello desencadena la etapa de selección, en la que los pequeños productores eligen de sus parcelas los árboles o residuos de árboles que destinarán para la producción de leña.

Existe una gran variedad de especies de madera apropiadas. Estas generalmente se encuentran en purmas, bosques relictos, sistemas agroforestales o plantaciones. Al igual que lo que sucede con el pie derecho, uno de los grandes atractivos de la producción de leña es que puede ser fabricada como un subproducto de otras actividades productivas. Por ejemplo, puede elaborarse de los árboles de guaba utilizados para producir sombra en la producción de café. De hecho, la guaba es una especie altamente demandada en el mercado de leña.

Los pequeños productores venden la madera a los distribuidores mayoristas ya sea como leña o árboles en pie. En el segundo caso, los distribuidores se encargan de contratar motosierristas, quienes llevan a cabo la tala del árbol y su trozado, el cual consiste en transformar las trozas resultantes de la tala en pequeñas secciones o cilindros, o piezas de leña. Estas actividades son realizadas con motosierra o hacha, dependiendo de los volúmenes aprovechados, y requieren del trabajo de una o dos personas. Los pequeños productores pueden llevar a cabo estas tareas para recibir una mayor remuneración.

Ocasionalmente, los pequeños productores venden leña por iniciativa propia, sin esperar pedidos de los distribuidores mayoristas. Generalmente lo hacen cuando necesitan generar ingresos rápidos ante una emergencia o necesidad. Para ello, se encargan de la tala y trozado del árbol, en ocasiones aprovechando los residuos de la extracción de árboles maderables. Una vez fabricado el producto, apilan la leña cerca de las carreteras para atraer la atención de distribuidores mayoristas. En estos casos, los pequeños productores reciben un pago mayor por la leña vendida.

Una vez producida la leña, esta es secada al aire libre con el fin de incrementar su rendimiento como combustible. Este proceso se puede realizar en el mismo lugar de extracción o en los centros de acopio de los distribuidores mayoristas en las zonas urbanas.

Finalmente, la leña es vendida como producto a los consumidores finales. Los mayoristas la venden a negocios de alimento -como panaderías, comercios de carne ahumada o productores de chancaca y de confitados de maní-, quienes la emplean en grandes cantidades. Años atrás, las ladrilleras locales también utilizaban leña como combustible, pero actualmente prefieren utilizar cascarilla de arroz por su menor precio y mayor disponibilidad. Por su parte, los minoristas se encargan de abastecer mercados de abastos y restaurantes pequeños. 

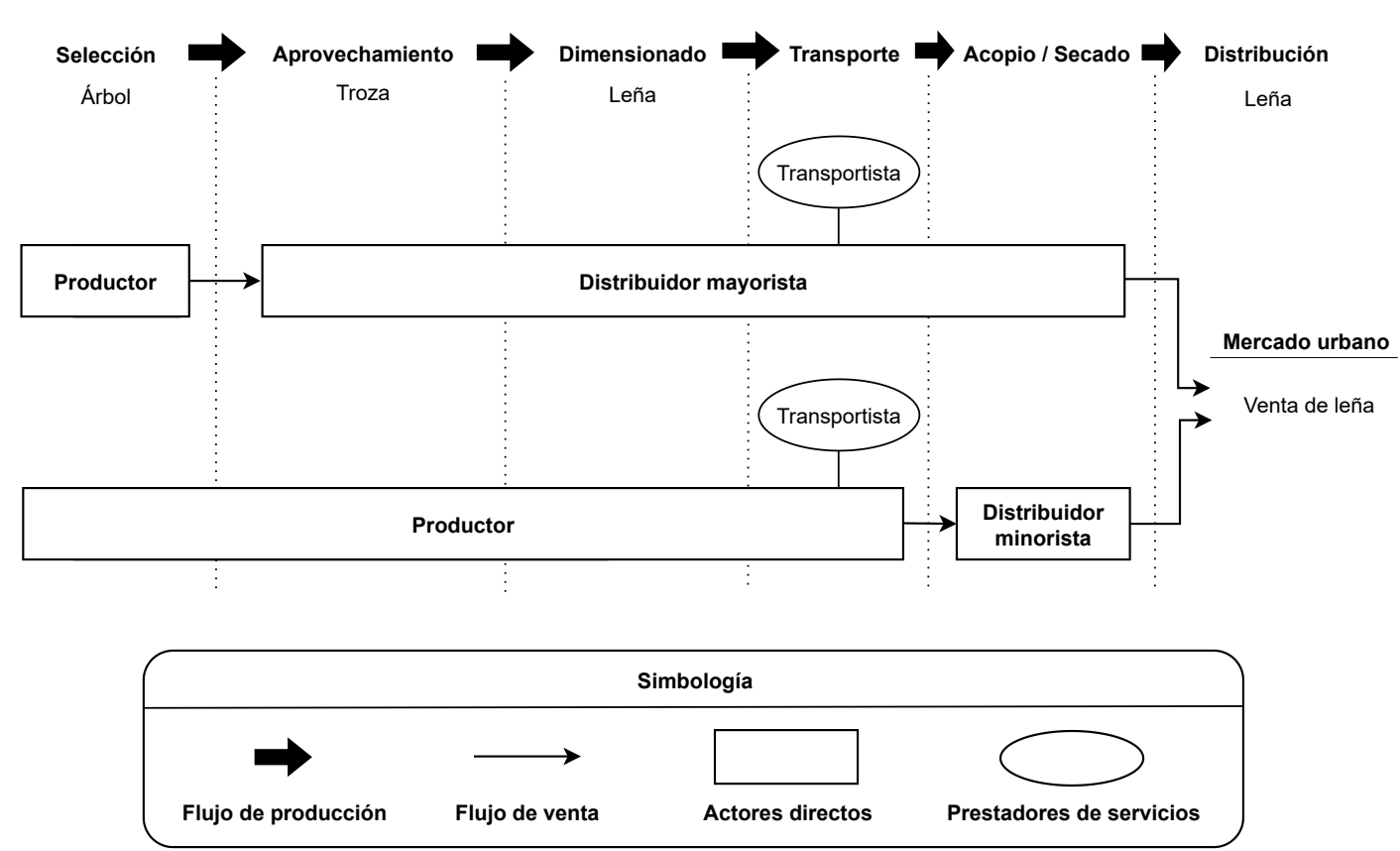

Figura 6. Cadena de valor de la leña

Para determinar los precios de venta de leña se utilizan distintas equivalencias. Las unidades pueden ser rajas, atados, cargas o furgonetas, las mismas que se describen a continuación:

- Las rajas: son unidades de leña, con dimensiones de $10 \mathrm{~cm}$ de diámetro y longitudes de 0,7 m o $1 \mathrm{~m}$.

- Los atados: tienen 10 unidades de leña. También conocidos como rollos o tercios.

- Las cargas: contienen 20 unidades de leña.

- Los furgones o furgonetas: contienen de 10 a 15 cargas de leña dependiendo de la especie (200 unidades de leña de madera dura o 300 unidades de leña de madera blanda).

En lo que respecta a los precios y costos en esta cadena de valor, estos varían constantemente en función de las condiciones específicas de cada acuerdo, de los precios en el mercado y de las cantidades de madera. En zonas urbanas, el precio final de la leña blanda es de $S / 0.3$ soles por leño aproximadamente, mientras que el de la leña dura es de alrededor de $\mathrm{S} / 0,75$ soles por leño. Según estimaron los informantes, la venta de árboles en pie genera a los pequeños productores una ganancia de aproximadamente $S / 0,06$ soles por unidad de leña. Por su parte, los distribuidores obtienen entre $\mathrm{S} / 0,07$ y $\mathrm{S} / 0,08$ soles de ganancia por unidad, tras descontar los costos de producción.

Al igual que en las cadenas de valor de madera aserrada y pie derecho, los pequeños productores cumplen un rol importante en la cadena de valor de la leña, al ser los principales proveedores de su materia prima. Sin embargo, dependen de la llegada de distribuidores para venderla, lo que limita sus posibilidades de negociar precios más favorables o de generar ingresos constantes por esta actividad. Aun cuando existe una gran demanda de leña en el mercado regional, los pequeños productores suelen comercializar este producto a pequeña escala y solo de manera esporádica.

Al respecto, observamos que los pequeños productores elaboran leña como una actividad económica secundaria, con el fin de complementar sus ingresos. La mayoría de los pequeños productores entrevistados comentaron haber vendido leña alguna vez. Asimismo, observamos que ninguno dedicaba tierra exclusivamente para la producción de leña, pero la obtienen con madera proveniente de tierras destinadas a otros fines. Al no requerir mayor inversión, la leña resulta un complemento atractivo.

Para promover que en el futuro esta actividad pueda ser practicada de manera constante, es necesario que los pequeños productores adquieran un mayor conocimiento de las características del mercado, a la vez que desarrollen sus capacidades de gestión, de modo que puedan hacer frente a la logística necesaria para vender la leña directamente a sus consumidores finales. 


\section{Especies utilizadas en la cadena de valor}

Para la producción de la leña, puede ser utilizada cualquier especie forestal maderable. Sin embargo, ciertas características de la madera determinan la calidad del producto y, por lo tanto, su precio en el mercado. Estas son: la duración de combustión -que define su rendimiento y rentabilidad-, la cantidad de humo que libera y su disponibilidad en los bosques locales.

Las especies de madera utilizadas para la producción de leña pueden distinguirse en función de su dureza. Las especies de madera blanda tienen menor duración de combustión y liberan más humo, pero están disponibles en mayores cantidades en los bosques locales. La leña de estas especies tiene precios relativamente bajos en comparación a la de maderas duras, y es utilizada principalmente por hogares y restaurantes.

Una especie común de madera blanda usada para producir leña es la guaba (Inga sp.), especie nativa caducifolia asociada a cultivos agroforestales de café. Entre los cinco y siete años posteriores al cultivo de café, al entrar en un periodo de descanso, las tierras se vuelven purmas o bosques secundarios. Durante este periodo, los árboles de guaba se propagan rápidamente en toda la extensión de la parcela. Terminado el periodo de descanso, para iniciar una nueva plantación de café, los pequeños productores deben retirar casi toda la vegetación, exceptuando los árboles más antiguos. De esta forma, obtienen madera de guaba en grandes cantidades, lo que resulta atractivo considerando que se trata de la especie de madera blanda con mayor duración de combustión.

Las especies de madera dura tienen mayor duración de combustión y liberan menor cantidad de humo, pero sus árboles existen en menor cantidad en los bosques locales y generalmente son utilizados en otras cadenas de valor. La leña de estas especies tiene el precio más alto en el mercado. Este tipo de leña es utilizado principalmente por panaderías y productoras de carnes ahumadas.

La leña de ingaina (Roupala obovata Kunth), por ejemplo, es la más requerida por los productores de cecina debido al sabor particular que confiere a las carnes; sin embargo, su poca disponibilidad en bosques locales los obliga a comprar leña de ingaina proveniente de otras regiones del país. La leña de uritoquiro (Copaifera sp.) reemplaza el uso de la ingaina ya que tienen características similares. Las leñas de uriamaba (Miconia sp.) y rufindi (Inga sp.) se utilizan principalmente por panaderías debido a la larga duración de su combustión.

Además de las especies mencionadas, existen otras que también se utilizan para fabricar leña, aunque de manera menos frecuente. Las de madera blanda incluyen la guayaba (Psidium guayava $L$.), el huarmi huarmi (sin identificar), el ushunquiro (Jacaranda sp.), el llausaquiro (sin identificar), la panguana (sin identificar) y la quillosisa (Vochysia ferrugínea Mart.). Respecto a las maderas duras, los informantes mencionaron que también utilizan el estoraque (Myroxilon balsamum), el porotillo (Erythrina fusca Lour.), la shaina (Columbrina glandulosa), el copal quiro (sin identificar) y el piñaquiro (Hieronyma oblonga). 


\section{Cuellos de botella}

Las secciones anteriores describen las cadenas de valor de madera aserrada, pie derecho y leña, tres cadenas donde las parcelas de pequeños productores son fuentes importantes de materia prima. Nuestro análisis señala que estos productos tienen el potencial de beneficiar a los pequeños productores en la región que en el futuro puedan aplicar a contratos de CUSAF. Sin embargo, este estudio también advierte que aún queda mucho por hacer para mejorar las condiciones en las que los pequeños productores participan de estas cadenas. En su estado actual, no permiten a los pequeños productores aprovechar al máximo sus oportunidades ni expandir su margen de ganancias.

A continuación se describen los cinco principales cuellos de botella para pequeños productores identificados en estas cadenas de valor, los cuales deben ser atendidos con el fin de promover la participación de pequeños productores en estas prácticas sostenibles y rentables.

\section{Falta de autorizaciones para que los pequeños productores puedan extraer y transportar madera:}

La mayoría de los pequeños productores locales no cuenta con autorización legal para extraer y transportar madera. En algunos casos, debido a que ocupan tierras de dominio público sobre las que no poseen título de propiedad. Esta carencia los inhabilita a tramitar una autorización legal para el aprovechamiento, transporte y comercialización de madera debido a que la normativa actual considera el título de propiedad como prerrequisito para obtenerla. A los agricultores en esta situación que habitan sus parcelas desde antes de 2011, el contrato de CUSAF les ofrece una alternativa para que puedan iniciar el proceso de producir legalmente, siempre y cuando estén dispuestos a cumplir con la normativa vigente.

Sin embargo, el hecho de que un pequeño productor esté habilitado para obtener un permiso de aprovechamiento no garantiza que pueda llegar a obtenerlo. Tanto los pequeños productores titulados como quienes postulan a contratos de CUSAF deben presentar declaraciones de manejo (DEMA) o registros de sus plantaciones para poder obtener el permiso de producción de madera aserrada. Estos requisitos para obtener dicha autorización suelen ser inaccesibles para la mayoría de los pequeños productores locales, sumado a que los trámites son muy costosos, demandan tiempo e implican viajes a la capital; logística e inversión que normalmente exceden sus posibilidades.

A ello se suma que las autoridades forestales -quienes acompañan a los pequeños productores en la elaboración de estos instrumentos-, por falta de presupuesto o de personal técnico contratado por el distrito, cumplen con estas obligaciones de manera insatisfactoria, dejando muchas de sus tareas en manos de ONG o de los mismos proveedores de madera.

Por estos motivos, actualmente la mayor parte de los pequeños productores de la región participa de las tres cadenas de valor de manera informal. Ello limita sus posibilidades al negociar con proveedores y distribuidores, quienes controlan el acceso a los mercados y tienen el poder de establecer los términos de venta, y obstaculiza sus intentos de expandir su negocio.

\section{Degradación de los bosques y desaparición de las especies de árboles con mayor demanda en sus parcelas:}

La falta de prácticas de manejo sostenible a lo largo de los años ha generado la sobreexplotación de varias de las especies maderables con mayor demanda en el mercado. Según informantes locales, actualmente la caoba y el cedro -dos especies muy valoradas en la fabricación de madera aserrada y leña-, ya no existen en volúmenes comerciales en los bosques remanentes. Otras especies que ya 
no se encuentran con frecuencia son el tornillo y la ingania. Adicionalmente, pequeños productores entrevistados informaron tener dificultades para encontrar árboles con diámetros mayores a $70 \mathrm{~cm}$.

Esta degradación es, en parte, consecuencia de la falta de incentivos que tienen los pequeños productores para invertir en restaurar sus parcelas o adoptar prácticas sostenibles de manejo. Al no contar con las autorizaciones necesarias para comercializar legalmente sus productos, ni tener la seguridad para invertir a largo plazo, sumado a la dificultad de acceder al apoyo requerido para establecer sus proyectos forestales o agroforestales; la sostenibilidad de la explotación de este recurso resulta un desafío grande. Se requiere de un plan a mediano y largo plazo, para lo cual es necesario contar con una estabilidad productiva que muchos pequeños productores locales carecen.

La informalidad, la falta de asistencia técnica y el limitado margen de acción de los pequeños productores son algunos de los factores que han contribuido a la agudización de este problema. De no revertirse esta tendencia, habrá graves consecuencias ecológicas y es posible que los insumos básicos de las cadenas de valor estudiadas disminuyan tanto que desaparezcan.

\section{Vulnerabilidad de los pequeños productores al negociar con actores más poderosos:}

Actualmente existen diversos factores que incrementan la dependencia de los pequeños productores de los proveedores y distribuidores para vender sus productos. Por un lado, vivir lejos de los centros urbanos limita su conocimiento sobre el funcionamiento del mercado, las oportunidades comerciales y las alternativas legales a su disposición. Esta misma lejanía agudiza sus dificultades para conseguir las autorizaciones necesarias para un proceder legal.

Esta vulnerabilidad se consolida cuando los pequeños productores negocian como individuos desarticulados. Como tales, son incapaces de producir los volúmenes demandados por los compradores finales, creando se así dependencia de los intermediarios y limitando sus posibilidades de negociar mejoras en las condiciones de venta. Lamentablemente, esta es la situación de la mayoría. Según los pequeños productores entrevistados, si bien en los distritos estudiados existen cooperativas agrícolas, estas no agrupan a todos los productores ni priorizan el tema forestal.

\section{Limitado acceso a la información sobre las condiciones del mercado y los procedimientos técnicos, y falta de herramientas financieras para la inversión:}

La falta de información de los pequeños productores sobre las condiciones del mercado y los procedimientos técnicos limita su capacidad de negociación con otros actores de las cadenas. Por ejemplo, todos los pequeños productores entrevistados mencionaron no saber cómo estimar los volúmenes del árbol a cortar ni calcular la cantidad de madera a obtener de este. Asimismo, cinco indicaron haber vendido parcelas enteras para leña sin conocer sus especies ni valor en el mercado. Ello evidencia una grave carencia de información al momento de negociar pues no se cuenta con las bases necesarias para evaluar si el precio acordado es el más apropiado.

La falta de información también limita las posibilidades de los pequeños productores al momento de tomar decisiones con miras a obtener mejores rendimientos económicos. Algunos productores ignoran que las especies que existen en sus parcelas tienen un alto valor en el mercado. Ese es el caso del laurel, que sirve para producir muebles; o de la bolaina y el bambú, útiles en la producción de pie derechos. En otros casos, desconocen que algunas especies comerciales tienen aplicaciones alternativas. Este es el caso del eucalipto, utilizado en la producción de madera aserrada, y cuya aptitud para producir pie derechos suele pasar inadvertida.

Los pequeños productores requieren fortalecer sus conocimientos sobre diversos temas, entre los que resaltan: cómo estimar el volumen de un árbol, cómo funciona el mercado, cuáles son los precios de venta de las diferentes especies, qué modalidades de venta existen y cuáles son los requisitos para operar de manera formal. 
La poca capacidad financiera de los productores limita su inversión en el mercado forestal e impide incrementar el valor de sus tierras. Al respecto, el mercado financiero no ofrece créditos orientados a los negocios forestales que, por lo general, tienen un retorno financiero a largo plazo. Esta limitante influye en que el productor no invierta en recuperar sus tierras forestales y priorice la producción agrícola.

\section{Poca visibilidad del rol de la mujer en las actividades productivas:}

Las mujeres cumplen un rol fundamental en la gestión de los sistemas de producción y del hogar en los distritos estudiados. Ellas participan con frecuencia en el manejo de las purmas y los sistemas agroforestales. Asimismo, son responsables de la venta de productos forestales como la leña.

Pese a ello, las iniciativas del gobierno que buscan fomentar el desarrollo forestal en la zona no han logrado reconocer la dimensión en la que su trabajo es fundamental en la organización productiva local. Por lo contrario, suelen concentrar su atención en trabajar con los varones de la comunidad. Es a ellos a quienes suelen entregar los incentivos, proveer la información, y con quienes coordinan el trabajo.

Incluso programas de titulación han tendido a privilegiar los derechos de los varones por sobre los de las mujeres, quienes tienen las mismas bases para exigir que se les reconozca legalmente como propietarias. En el futuro, para lograr proyectos más efectivos y justos, será necesario hacer partícipes a todos los actores. Las nuevas iniciativas del gobierno-, entre ellas los contratos de CUSAF, deberán hacer frente a este urgente reto. 


\section{Recomendaciones}

Para superar los cuellos de botella identificados y promover que en el futuro la participación de los pequeños productores en estas cadenas de valor los provea de medios de vida sostenibles y rentables, este estudio propone las siguientes cinco recomendaciones:

\section{Ajustar la normativa para incentivar el manejo sostenible de productos forestales y su comercialización en mercados formales:}

En el futuro, los contratos de CUSAF brindarán una alternativa para que los pequeños productores de la región puedan formalizar sus actividades productivas, incluso sin contar con títulos de propiedad, siempre y cuando desempeñen actividades sostenibles. Sin embargo, de no tomarse medidas adicionales para facilitar el cumplimiento de los requisitos por parte de los pequeños productores, esta alternativa podría tornarse en una mera formalidad y no lograr su impacto deseado. Para que beneficie realmente a los productores, debe estar acompañada por un esfuerzo de simplificación y agilización administrativa por parte del gobierno regional.

Se recomienda al gobierno regional unificar su sistema de levantamiento de información. Para emitir un contrato CUSAF, el gobierno debe ubicar geográficamente las áreas reclamadas por los productores y presentar información relevante al respecto, lo que implica viajar a la localidad. Sugerimos aprovechar ese esfuerzo para simultáneamente levantar la información que se necesita para el registro de plantaciones: el detalle de las áreas que funcionan como bosques remanentes, plantaciones, sistemas agroforestales o purmas al interior de la parcela. Ello evitará duplicar esfuerzos administrativos y reducirá los costos de los procedimientos. De ese modo, facilitaría el registro de áreas agroforestales y plantaciones en el Registro Nacional de Plantaciones Forestales. A la vez que aliviaría el proceso para obtener autorizaciones de manejo de bosques secundarios o remanentes. Incluso, podría servir para recoger la información necesaria para la elaboración de las DEMA para el aprovechamiento de purmas y á arboles individuales en los sistemas agroforestales.

Por otro lado, se recomienda aprovechar esta información para canalizar incentivos, facilitar inversiones y diseñar estrategias. De esta manera, se promoverá el desarrollo de condiciones favorables para que los pequeños productores puedan formalizarse.

Finalmente, se recomienda hacer los cambios normativos necesarios para ajustar los procedimientos a la realidad de los pequeños productores locales y promover el máximo aprovechamiento de sus potenciales. Al respecto, sugerimos modificar los diámetros mínimos de corta para algunas especies, a fin de permitir que la leña y el pie derecho sean reconocidos como parte de los productos de las plantaciones y sistemas agroforestales. Ello permitirá que estos subproductos -de producción sencilla y barata- puedan subvencionar los sistemas en sus primeros años.

\section{Desarrollar estrategias para promover plantaciones y sistemas de agroforestería con pequeños productores:}

En el pasado, el gobierno regional ha promovido programas de incentivos y apoyo técnico para plantaciones con pequeños productores, pero estos han sido limitados y finalmente descontinuados. Según informantes locales, algunos de los principales problemas de tales programas han sido: promover especies no aptas para la zona, privilegiar el desarrollo de monocultivos sobre los sistemas diversificados, y no tomar en cuenta la experiencia y el conocimiento de los agricultores locales. 
El desarrollo de plantaciones forestales y sistemas de agroforestería con pequeños productores locales podría permitir recuperar la población de especies sobreexplotadas como la ingaina, uriamaba y rufindi, en la producción de leña; y la moena, cedro, laurel y capirona, en la de madera aserrada. Además de aprovechar de manera más eficiente especies subutilizadas, como el bambú en la producción de pie derecho; lo que a su vez permitiría proteger árboles semilleros, repoblar bosques remanentes e instalar plantaciones en áreas de recuperación.

Actualmente ya existen sistemas agroforestales desarrollados por agricultores locales, pero estos carecen de apoyo técnico y financiero. Ello se debe en parte a su falta de reconocimiento oficial. Dentro de la normativa actual, el manejo de la regeneración natural en purmas para la producción de especies como la bolaina, capirona, pájaro bobo o shaina, no es considerado como una actividad de plantación forestal. Ello se debe, en parte, a que la producción de leña y pie derechos utiliza árboles con diámetros menores a los $15 \mathrm{~cm}$, medida por debajo del diámetro mínimo de corta establecido en la normativa para plantaciones forestales.

Sugerimos modificar la normativa para incorporar el pie derecho y la leña como productos de los sistemas agroforestales y plantaciones. Ello sentaría las bases para que una práctica, que ya es parte del ciclo agrícola de subsistencia en la zona, pueda llevarse a cabo de manera formal. Asimismo, permitiría que el pie derecho y la leña -dos productos que requieren de baja inversión y tecnología, y que pueden ser fabricados en base a diversas especies de árboles comunes en las purmas localescomplementen los ingresos de los productores y subvencionen los sistemas agroforestales formales en sus primeros años.

Por otro lado, recomendamos al gobierno regional destinar personal y presupuesto para promover el establecimiento de plantaciones forestales y sistemas de agroforestería con pequeños productores; y diseñar los proyectos partiendo del aprendizaje, la experiencia y el conocimiento de los agricultores locales. Al respecto, sugerimos que se reconozca y valore la estrategia de los pequeños productores de implementar en sus sistemas agroforestales mosaicos productivos dinámicos y diversos; y que desista en la promoción de plantaciones de monocultivos. Finalmente, recomendamos promover el uso de especies seleccionadas por los mismos agricultores en los proyectos, que a su vez tengan demanda en el mercado local.

\section{Fortalecer la organización de pequeños productores:}

Se recomienda al gobierno regional y a las ONG canalizar esfuerzos para promover la organización de los pequeños productores locales, ya sea a través de la creación de cooperativas o mediante el fortalecimiento de las organizaciones existentes. Actualmente existen cooperativas agrícolas y de café que agrupan a ciertos productores, pero el centro de su atención no es la producción forestal.

Del mismo modo, recomendamos promover que estas organizaciones incluyan los siguientes objetivos:

- Encontrar soluciones colectivas a problemas comunes: como tramitar colectivamente las autorizaciones y permisos forestales de los miembros del grupo, o cooperar con el gobierno para fiscalizar el cumplimiento de normas y acuerdos.

- Facilitar la difusión de apoyo técnico, información y asistencia administrativa: por ejemplo, asistiendo en la ejecución de trámites, consolidando sistemas de apoyo, promoviendo el cumplimiento normativo, orientando la adaptación innovadora, creando lazos con otros actores del mercado o motivando talleres de fortalecimiento de capacidades.

- Mediar la negociación entre pequeños productores y mayoristas o compradores industriales: por ejemplo, participando de mesas de discusión, como la mesa Regional Forestal y de Fauna Silvestre de San Martín, o mediando las negociaciones con inversionistas o compradores. 
Con respecto al último punto, al negociar como colectivo los pequeños productores podrán ofrecer productos a escalas mayores. Ello les permitirá tener más poder de negociación, obtener mejores precios y negociar directamente con los consumidores finales.

Finalmente, se recomienda promover el acceso de estas organizaciones a recursos financieros en forma de créditos o subvenciones para que puedan invertir en su desarrollo y operar de manera sostenible.

\section{Fortalecer capacidades comerciales, técnicas y financieras de los pequeños productores:}

Se recomienda al gobierno regional y a las ONG facilitar el acceso de los pequeños productores a información sobre el mercado y la normativa. Con más información y acceso legal a los mercados, los pequeños productores podrían experimentar para crear estrategias innovadoras de producción sostenible que respondan a las características particulares de sus realidades.

Asimismo, se recomienda mejorar el acceso de los pequeños productores a información sobre los precios de las maderas o las especies con mayor valor comercial. Ello serviría como incentivo para invertir en la producción de estas especies. Del mismo modo, se recomienda llevar a cabo talleres prácticos en los que los pequeños productores puedan desarrollar capacidades de administración y comercio, como calcular el volumen de la madera o planificar el trabajo a mediano y largo plazo.

También es necesario generar instrumentos financieros que permitan la inversión en la producción de madera aserrada y pie derecho, y dar valor agregado a estos productos. Los créditos ofertados a los productores no consideran las características de estos mercados y solo están orientados a la producción agrícola de corto plazo. Es importante facilitar el acceso de los productores a recursos financieros que les permitan incrementar el valor de sus tierras forestales.

\section{Adaptar los planes a estrategias inclusivas en materia de género:}

Se recomienda al gobierno regional que sus programas e iniciativas de apoyo desarrollen estrategias inclusivas en materia de género, que garanticen que tanto hombres como mujeres participen equitativamente. Algunas de estas estrategias pueden ser:

- Ser claros al indicar que tanto hombres como mujeres pueden participar de estos programas o iniciativas.

- Asegurarse de proveer información en los formatos que las mujeres prefieran.

- Organizar reuniones en lugares donde las mujeres puedan atender y en momentos del día en el que estén disponibles.

- Reservar un espacio para mujeres en los cursos de capacitación.

- Garantizar que los equipos de extensión y de capacitación incluyan representantes mujeres.

Adicionalmente, se recomienda verificar que la información provista sea de interés para las mujeres, para lo cual se podría indagar periódicamente qué tan útil consideran ellas la información que reciben. Esto permitirá conocer mejor sus necesidades e intereses en materia de información y adaptar, en consecuencia, las estrategias comunicativas.

Finalmente, se recomienda que estos programas e iniciativas incluyan indicadores que permitan evaluar el progreso de los programas y sus beneficios, tanto para hombres como mujeres. 


\section{Referencias}

Álvarez, H. y Fernández, J. (1992). Fundamentos teóricos del secado de la madera (pp. 44-45). Madrid: MAP.

Antezana, I., Bernet, T., López, G. y Oros, R. (2008). Enfoque Participativo en Cadenas Productivas (EPCP). Centro Internacional de la Papa.

Centro Agronómico Tropical de Investigación y Enseñanza, CATIE. (1994). Laurel, Cordia alliodora (Ruiz y Pavón) Oken, especie de árbol de uso múltiple en América Central. (p. 41).

Confederación Peruana de la Madera (2008). Compendio de información técnica de 32 especies forestales, Tomo I y II. Lima: Edición CITE madera. Derechos Reservados.

Freitas da Silva, M., Medeiros, L. y Angélica de Lima, C. (1992). Leguminosas da Amazônia brasileira II Cedrelinga Ducke (Leg. Mimos.).- Belém.

Hildebrand, P.E. (1981). Combining disciplines in rapid appraisal: the Sondeo approach. Agricultural Administration, 8(6), (pp.423-432).

Autoridad Nacional del Agua. (1982). Inventario y evaluación integral de los recursos naturales de la Zona del Alto Mayo. Volumen N² 2, (pp. 75-80).

Laínez, A. (2006). Experiencias Agroforestales en el Alto Mayo. Informe Final. Proyecto de Cuencas Andinas y Programa de Desarrollo Rural Sostenible. Cooperación Alemana para el Desarrollo -. GIZ

Londoño, X. (2010). Identificación taxonómica de los bambúes de la región noroccidental del Perú.

Mendieta, O. y Abad, J. (1991). Identificación y Análisis bromatológico de dos especies de hongos comestibles silvestres, Programa de Manejo Ambiente -, PEHCBM, (p. 10).

Poore, M.E.D. y Fries, C. (1987). Efectos ecológicos de los eucaliptos (The ecological effects on eucalyptus) (No. FAO FP-59). Roma: FAO.

Reynel, C., Pennington, T.D., Flores, C. y Daza, A. (2003). Árboles útiles de la Amazonía Peruana y sus usos. Lima.

SERFOR (2016).Lista oficial de especies forestales. Resolución de dirección ejecutiva №143-2016SERFOR-, Anexo N ${ }^{\circ} 01$.

Toro, D., Kroll, B. y Varese, E. (2016). Café 2.0 Climáticamente inteligente. Proyecto: Caficultura, conocimiento y carbono para REDD en el Perú (CCC). Stichting Interkerkelijke Aktie Voor Latijns Amerika 'SOLIDARIDAD'. 


\section{Annexos}

Anexo 1. Actores entrevistados en la primera fase del estudio en San Martín

\begin{tabular}{|c|c|c|c|}
\hline \multirow{2}{*}{ Grupo } & \multicolumn{2}{|l|}{ Lugar } & \multirow{2}{*}{ Actores } \\
\hline & Provincia & Distrito & \\
\hline \multirow{22}{*}{$\begin{array}{l}\text { Comerciantes y } \\
\text { productores }\end{array}$} & \multirow{3}{*}{ San Martín } & \multirow{3}{*}{ Tarapoto } & Mercado municipal N² \\
\hline & & & Mercado privado «El huequito» \\
\hline & & & Comerciantes ambulantes \\
\hline & \multirow{3}{*}{ Lamas } & \multirow{3}{*}{ Lamas } & Mercado municipal central \\
\hline & & & Puestos privados alrededor del mercado \\
\hline & & & Comerciantes ambulantes \\
\hline & \multirow{16}{*}{ Moyobamba } & \multirow{9}{*}{ Moyobamba } & Mercado municipal central \\
\hline & & & Mercado municipal «Ayayama» \\
\hline & & & Mercado privado «Erick» \\
\hline & & & Mercado privado «Paquito» \\
\hline & & & Mercado privado «Alto Mayo» \\
\hline & & & Comerciantes ambulantes \\
\hline & & & Vivero "Selva Verde" \\
\hline & & & Puerto Tahuishco \\
\hline & & & Aserraderos y carpinterías \\
\hline & & \multirow{4}{*}{ Jepelacio } & Mercado municipal \\
\hline & & & Productores \\
\hline & & & Carpintería \\
\hline & & & Artesano \\
\hline & & \multirow{3}{*}{ Soritor } & Mercado municipal \\
\hline & & & Productores \\
\hline & & & Artesanas \\
\hline Socios cooperantes & \multirow{4}{*}{ Moyobamba } & \multirow{4}{*}{ Moyobamba } & $\begin{array}{l}\text { Organización Solidaridad - coordinador y } \\
\text { supervisor de campo del proyecto sobre sistemas } \\
\text { agroforestales con productores de café y cacao. }\end{array}$ \\
\hline \multirow{3}{*}{$\begin{array}{l}\text { Agentes de } \\
\text { gobierno }\end{array}$} & & & $\begin{array}{l}\text { Autoridad Regional Ambiental (ARA), Dirección de } \\
\text { medio ambiente. }\end{array}$ \\
\hline & & & $\begin{array}{l}\text { Proyecto Especial Alto Mayo (PEAM), Dirección de } \\
\text { desarrollo agropecuario. }\end{array}$ \\
\hline & & & $\begin{array}{l}\text { Proyecto Especial Alto Mayo (PEAM), Dirección de } \\
\text { manejo ambiental. }\end{array}$ \\
\hline
\end{tabular}


Anexo 2. Frutos observados en los mercados en Moyobamba

\begin{tabular}{ll}
\hline \multicolumn{1}{c}{ Nombre común } & \multicolumn{1}{c}{ Nombre científico } \\
\hline Aguaje & Mauritia flexuosa \\
\hline Carambola & Averrhoa carambola \\
\hline Chope & Gustavia longifolia \\
\hline Cocona local & Solanum sp. \\
\hline Guayaba & Psidium guayaba \\
\hline Indano & Byrsonima crassifolia \\
\hline Inga - Guaba & Inga edulis \\
\hline Inga - Pacae & Inga sp. \\
\hline Inga - Shimbillo & Inga sp. \\
\hline Limón injerto & Citrus sp. \\
\hline Limón mandarina & Citrus sp. \\
\hline Macadamia & Macadamia integrifolia \\
\hline Morera & Morus alba \\
\hline Palta & Persea americana \\
\hline Piña cayena & Ananas comosus L. \\
\hline Plátano & Musa sp. \\
\hline Pomarosa & Syzygium jambos \\
\hline Shica shica & Aiphanes horrida \\
\hline
\end{tabular}


CIFOR Working Papers contain preliminary or advance research results on tropical forest issues that need to be published in a timely manner to inform and promote discussion. This content has been internally reviewed but has not undergone external peer review.

Este documento presenta un análisis de las cadenas de valor forestales que involucran a los pequeños productores en San Martín, Perú. La investigación se llevó a cabo en el marco del proyecto PARA "Piloting Approaches to Rural Advisory Services in Support of Scaling the Agroforestry Concessions Scheme in Perú", una iniciativa implementada por el Centro Internacional de Investigación Agroforestal (ICRAF), en convenio con la ONG Solidaridad, el Centro de Investigación Forestal Internacional (CIFOR) y la Universidad de Freiburg, y financiado por el Ministerio Federal Alemán de Cooperación Económica y Desarrollo (BMZ) por encargo de la Deutsche Gesellschaft für Internationale Zusammenarbeit (GIZ) a través del Fondo Internacional de Investigación Agrícola (FIA). Este estudio evaluó las cadenas de valor forestales que ofrecen oportunidades para pequeños productores elegibles para recibir contratos CUSAF en la provincia de Moyobamba, departamento de San Martín. El objetivo fue identificar aquellos productos y sistemas con mayor potencial para diversificar los medios de vida de los pequeños productores locales, y las condiciones necesarias para promover que tengan una participación rentable y sostenible en estas cadenas de valor. Este informe describe las cadenas de valor de tres productos identificados con mayor potencial para beneficiar a los pequeños productores (madera aserrada, puntales, leña); analiza el rol que cumplen actualmente en estas cadenas, los retos que enfrentan; y ofrece recomendaciones para incrementar sus oportunidades.

\begin{tabular}{|l|l|l|} 
& $\begin{array}{l}\text { El Programa de Investigación de CGIAR sobre Bosques, Árboles y Agroforestería (FTA) es el } \\
\text { programa de investigación para el desarrollo más grande del mundo dedicado a destacar el } \\
\text { papel de los bosques, los árboles y la agroforestería para el desarrollo sostenible, la seguridad }\end{array}$ \\
CGIAR & $\begin{array}{l}\text { PROGRAMA DE } \\
\text { INVESTIGACIÓN SOBRE } \\
\text { Bosques, Árboles y y }\end{array}$ & $\begin{array}{l}\text { alimentaria, y frente al cambio climático. CIFOR dirige el programa FTA en asociación con } \\
\text { ICRAF, la Alianza Bioversity International-CIAT, CATIE, CIRAD, INBAR y TBI. }\end{array}$ \\
& La investigación del Programa FTA cuenta con el apoyo del Fondo Fiduciario del CGIAR: cgiar. \\
org/funders
\end{tabular}

\section{cifor.org | forestsnews.cifor.org}

\section{旅 PARA}
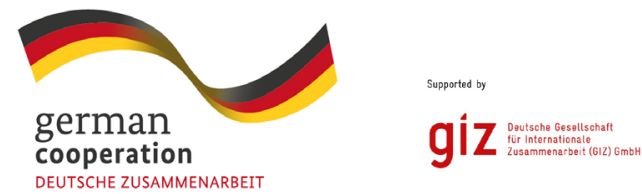

Centro para la Investigación Forestal Internacional (CIFOR)

CIFOR promueve el bienestar humano, la integridad del medio ambiente y la equidad mediante investigación de avanzada, desarrollando las capacidades de sus socios y dialogando activamente con todos los actores involucrados, para informar sobre las políticas y las prácticas que afectan a los bosques y a las personas. CIFOR es un centro de investigación CGIAR y lidera su Programa de Investigación sobre Bosques, Árboles y Agroforestería (FTA por sus siglas en inglés). Nuestra sede central se encuentra en Bogor, Indonesia, y contamos con oficinas en Nairobi, Kenia; Yaundé, Camerún; Lima, Perú, y Bonn, Alemania.

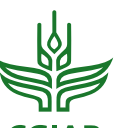

